\title{
Modelling the Impact of Leaky Barriers with a 1D Godunov-Type Scheme for the Shallow Water Equations
}

\author{
Shannon Leakey $\mathbb{D}^{(}$, Caspar J. M. Hewett *(D), Vassilis Glenis ${ }^{(1)}$ and Paul F. Quinn \\ School of Engineering, Newcastle University, Newcastle upon Tyne NE1 7RU, UK; \\ s.c.leakey2@newcastle.ac.uk (S.L.); vassilis.glenis@newcastle.ac.uk (V.G.); p.f.quinn@newcastle.ac.uk (P.F.Q.) \\ * Correspondence: caspar.hewett@newcastle.ac.uk
}

Received: 13 December 2019; Accepted: 21 January 2020; Published: 30 January 2020

\begin{abstract}
There is increasing interest in distributing small-scale interventions across the landscape as an alternative means of reducing flood risk. One such intervention, the leaky barrier, is introduced in channels to slow down high flows and encourage temporary storage on the floodplain. While these barriers have been implemented widely, there is still resistance to their use at the scales required to impact significantly on flood risk, at least partially due to an evidence gap. In particular, there is no standard method for representing leaky barriers in hydraulic models. This study sets out a methodology for developing mathematical models which capture the hydraulics of leaky barriers accurately, allowing key questions about their combined behaviour in catchments to be answered. A 1D Godunov-type scheme is set up and leaky barriers incorporated with internal boundary conditions. This model is tested against benchmarks from the literature and new steady-state data, and then run predictively on transient cases. The method will help to answer key questions about the optimal leakiness of small-scale interventions, the limits to their usefulness, and how combinations of barriers may or may not cause synchronisation problems when the effect of multiple barriers is aggregated.
\end{abstract}

Keywords: hydraulic modelling; finite volume method; Godunov-type scheme; hydraulic flume; nature-based solutions; sustainable drainage systems; runoff attenuation features; leaky barriers; woody debris; log jams

\section{Introduction}

Flooding is one of the great issues of our time, representing the world's most damaging environmental hazard [1-3]. The pattern of land use change in both the developed and developing world over the last century has been a key driver for increasing the risk of flooding. Most notably, urban development has had a widely recognised impact, representing a direct change from high infiltration to low infiltration [4]. Moreover, post-Green Revolution intensification of farming has increased surface runoff pathways and soil erosion, as well as introducing diffuse pollution in the form of nutrients and pesticides into waterways [5]. These impact not only on flood risk, but on numerous environmental factors including water quality, river morphology, habitats and biodiversity. While these changes are well researched and understood [6-9], solving the problems associated with them remains a major challenge. In addition, climate change poses a further threat to urban and rural catchments via wetter winters and more intense summer storms $[10,11]$.

These current and potential future threats provide a backdrop for increasing interest in moving away from large traditional engineered structures to large numbers of small-scale interventions distributed across the landscape with a focus on approaches that mimic or work with natural 
processes. Numerous terms are used to describe such interventions, including Ecological Engineering [12], Catchment Systems Engineering [13,14], Nature-Based Solutions [15,16], Natural Flood Management [17-19], Natural Infrastructure [20], Engineering with Nature [21] and Working with Natural Processes [22]. In urban settings this is paralleled by developments such as Green Infrastructure $[23,24]$ and Sustainable Drainage Systems [25,26].

Alongside reducing flood risk, nature-based interventions can also reduce diffuse pollution and sediment export, or improve biodiversity and carbon accumulation [16]. Some interventions fall in the category of Runoff Attenuation Features (RAFs): soft-engineering interventions in agricultural catchments designed to slow flow and create temporary storage of water during periods of high flow [27-29]. Examples include strategically placed leaky barriers and creation of temporary storage ponds. RAFs are generally designed to target extreme flows, taking account of factors such as the need to maintain high conveyance rates in floods, improving recharge rates and avoiding impoundment of water needed by downstream communities. They provide the multiple benefits of reducing flood risk, diffuse pollution from farming and soil erosion [13]. If a RAF intercepts the channel network or an overflow path, it is called an online RAF. Otherwise it is called an offline RAF [30].

Leaky barriers are described in the literature by a plethora of terms including large woody debris [31], woody debris structures [32], woody debris jams [33], engineered log jams [34] and leaky dams [35]. One key effect of such barriers is that they reduce flow velocities and add friction to the catchment system $[30,36]$. They can be created by natural processes, for example, barriers formed by trees falling into waterways [37]. However, many of these natural barriers in river systems have been removed in recent decades [38] which has given rise to an interest in installing engineered leaky barriers in river catchments. Such structures aim to mimic the effect of natural leaky barriers, acting as small RAFs that allow low flows to pass under or through them unimpeded, but causing high flows to back up, creating temporary storage in the channel and encouraging water onto the floodplain $[28,35]$.

Engineered leaky barriers may be constructed in a variety of designs, ranging from small structures that only impede the flow a little to less leaky, more engineered "wedged log" or "horse jump" dams $[39,40]$. The designs used vary hugely, in part due to cost, location and what materials are readily available, but most pertinently because there are few or no design criteria available [32,41,42]. This could be due to our inadequate understanding of the effects of leaky barriers on turbulent flow and the fluid forces acting on the barriers [34]. Such knowledge could inform and improve design criteria, leading to optimal design. However, it is challenging to study leaky barriers in the field. This is because data are generally limited before intervention and, once a barrier is in place, investigating its effects depends on varying degrees of rainfall, including large storms [2,22]. It is also worth noting that, given that the effect on flow of an individual leaky barrier is small, a large number are required to have a significant effect at a catchment scale [43]. For example, in the UK, 457 leaky barriers have been installed in Calderdale [44] and 167 in Pickering [45,46]. This requirement for a large number of barriers means that scaling is a key problem $[35,43,47,48]$. Moreover, there are concerns that installing large numbers of barriers across a catchment could lead to synchronisation issues. This is where the timing means that peaks coincide from different sub-catchments [49], resulting in greater flooding than when there were no interventions. Mathematical modelling is the obvious way to attempt to overcome these problems, but there are limited options for modelling RAFs [50] and, in particular, there is no accepted way of representing leaky barriers in models [22,51].

The simplest method is to circumvent the modelling problem by not modelling the barriers themselves, but rather using their measured effect to drive another model. This was done for Pickering with a 2D hydraulic model [46]. As other RAFs besides leaky barriers were implemented at Pickering, this method could not isolate the effects of the leaky barriers. A more direct modelling approach would be more reliable and more useful for planning.

The flood-excess volume method [43] is the simplest way to model leaky barriers directly. Here, the volume of temporary storage provided by the barriers is estimated, and then it is removed from the flood hydrograph. For example, the storage volumes behind online and offline barriers have been 
estimated with 1D hydraulic models [45] and hydrological GIS tools [52]. This approach assumes the barrier is empty before the flood event, and so would not be effective at modelling multi-peak events. Also, it neglects any losses through the barrier walls, and it does not consider the location of the barriers. These problems mean that the modelled effects of the interventions are likely to be overestimates. Ideally, there would be a way to include leaky barriers in the hydrological and hydraulic models themselves.

A popular method for including leaky barriers in a model is to change parameters at the location of the barriers. For example, online barriers are often represented as increased values of Manning's $n$, both in hydrological models $[36,53]$ and hydraulic models $[54,55]$. However, even if these parameter values come from the field, it is inappropriate to apply them to other sites or flow conditions [56]. Moreover, an increased Manning's $n$ will impact low flows as well as high flows, and so this would not be a good model of barriers that let low flows through unimpeded. In fact, an increased Manning's $n$ will have little effect on steeper slopes [36,57], but a leaky barrier is going to provide an obstruction either way.

A more physically-based way to model online barriers is by altering the channel geometry. For example, they have been modelled as partial blockages [47] and reduced cross-sections based on field data [58], both in 1D hydraulic models. This has a different effect to changing the roughness. Indeed, while increasing the roughness reduces velocities, decreasing the cross-sectional area increases velocities [58].

Leaky barriers can also be modelled by comparing them to well-understood hydraulic structures. For example, weir equations have been used to study the behaviour of different barrier designs - full brow, rectangular slot, V-notch, inverted V-notch, letterbox slot-as part of a hydrological model describing the ponded water behind each barrier [59]. Another option is to model leaky barriers as sluice gates with weir overflow, as was done to route the runoff from Dynamic-Topmodel [28] and as part of a simple network model [35]. While these representations have more potential to replicate the real-life behaviour of online and offline barriers, they were not validated with data. We are constrained by the theoretical and empirical equations that already exist.

There are limited detailed measurements of what happens at leaky barriers, and so there is no agreed-upon way to represent leaky barriers in models. Without further investigation, it is impossible to know if real leaky barriers will behave as high values of Manning's $n$, reductions in cross-sectional area, or weirs/sluice gates. To get a clearer idea of how leaky barriers behave in isolation, they have to be investigated in isolation. In particular, a recent review paper [56] has recommended that the hydraulic structure method be investigated in more detail. The aim of the present study is to develop a methodology to model leaky barriers in catchments, using a combination of physical and mathematical models. A 1D hydraulic model that includes leaky barriers as hydraulic structures is developed and then tested against experimental data obtained from a controlled hydraulic flume. The results suggest that internal boundary conditions provide a promising method for including leaky barriers as hydraulic structures in mathematical models.

\section{Materials and Methods}

\subsection{Conceptual Model}

Figure 1a shows how the physical model of the leaky barrier consists of a single horizontal aluminium sheet with a gap underneath. Some flow will always pass under the barrier and, in high flows, there will be flow over the barrier too. In the terminology from the literature, the barrier is like an underflow jam [60]. Such barriers have been modelled by adding together the sluice gate and rectangular weir equations $[28,35]$.

The physically-based models of [61] suggest that there are five possible operating stages for a combined gate and weir structure, as illustrated in Figure 1c. These are: 
1. Gate operating freely, no weir overflow

2. Gate submerged by tailwater, no weir overflow

3. Gate and weir operating freely

4. Gate submerged by tailwater, weir operating freely

5. Gate and weir submerged by tailwater

In stages $1-2$, the barrier acts as a sluice gate, while in stages $3-5$, the barrier acts as a combined sluice gate and rectangular weir. The differences within these two groups depend on the depth of the tailwater and the location of the associated hydraulic jump. Different discharge equations are used if a gate is operating freely, as in stages 1 and 3, or with its vena contracta submerged by a hydraulic jump, as in stages 2, 4, and 5 [62]. Similarly, different discharge equations are used if a weir is operating freely, as in stages 3 and 4 , or if it is submerged, as in stage 5. Although in reality the gate and weir flows will interact [63-65], the interaction is ignored in the present study, and the gate and weir discharges are simply added together.

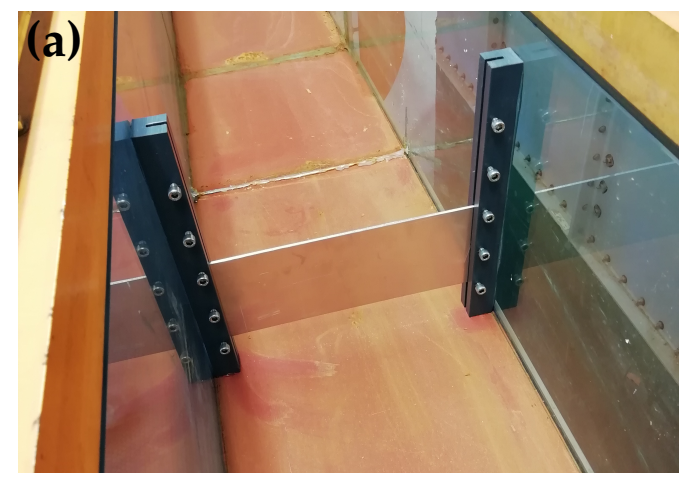

\section{(b)}

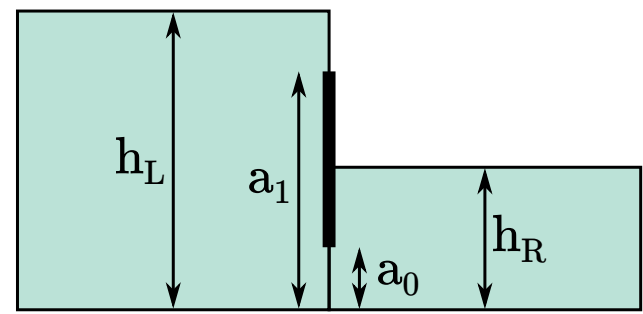

(c)
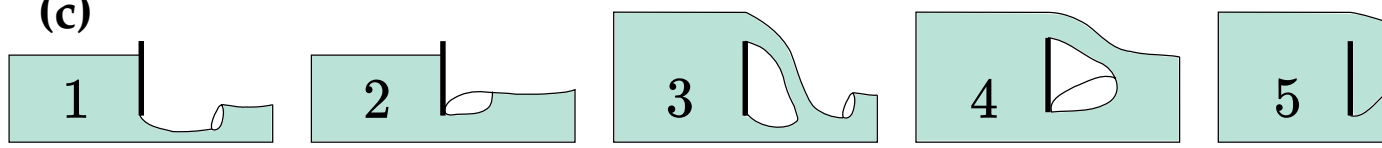

Figure 1. The leaky barrier model. (a) Physical model in the hydraulic flume. (b) Definition sketch for left-to-right flow. (c) Five operating stages, based partially on [61].

\subsection{Flume Experiments}

Physical modelling was undertaken in a hydraulic flume at Newcastle University. The flume has length $17.95 \mathrm{~m}$, width $0.294 \mathrm{~m}$, and slope 1:1600. Calibration of the flume gave a Manning's $n$ of 0.009. A leaky barrier was placed at $x=11.14 \mathrm{~m}$ along the length of the flume, using slots on either side of the flume to fix it in place, as shown in Figure 1a. These slots reduced the barrier width to $0.264 \mathrm{~m}$. Let the depth of the base of the leaky barrier be $a_{0}$ and the top $a_{1}$, as in Figure $1 \mathrm{~b}$. Four barrier configurations were tested, each for a range of steady-state flow conditions:

(a) No barrier, 1 experiment;

(b) $\quad\left(a_{0}=0.05 \mathrm{~m}, a_{1}=0.15 \mathrm{~m}\right), 7$ free flow experiments;

(c) $\quad\left(a_{0}=0.05 \mathrm{~m}, a_{1}=0.1 \mathrm{~m}\right), 15$ free flow experiments; and

(d) $\left(a_{0}=0.025 \mathrm{~m}, a_{1}=0.125 \mathrm{~m}\right), 30$ free flow and 2 submerged experiments.

"Free flow" refers to stages 1 and 3, or scenarios where the leaky barrier is not touched, and "submerged" refers to stages 2, 4 and 5, where the downstream tailwater affects the flow through the barrier. Depth measurements were taken at six fixed points along the flume, two upstream of the barrier and four downstream:

$$
h_{10}, h_{11}, h_{11.3}, h_{12}, h_{13}, h_{17.8}
$$


where the subscript denotes the distance in metres along the flume. For (c) and (d), two additional depth measurements were taken for the free-flow experiments, one either side of the downstream hydraulic jump.

For each of the 55 flume experiments, the steady-state discharge was measured using a manometer $\left(q_{\text {man }}\right)$. For (a), (b) and (d), a velocity meter was also used to calculate the discharge $\left(q_{v e l}\right)$. It was found that the manometer and velocity-meter discharges did not agree. The equation

$$
q_{v e l}=0.00286+1.08 \cdot q_{\text {man }}
$$

describes the relationship for (d) with $R^{2}=0.99$, as plotted in Figure 2. In case (c), there were no $q_{v e l}$ data. However, the velocity meter was known to give more accurate results than the manometer. Therefore, for consistency, the regression Equation (2) was used to generate $q_{v e l}$ values from measured values of $q_{\operatorname{man}}$ for all cases. This transformed discharge is assumed to be an unbiased measurement for the remainder of the paper.

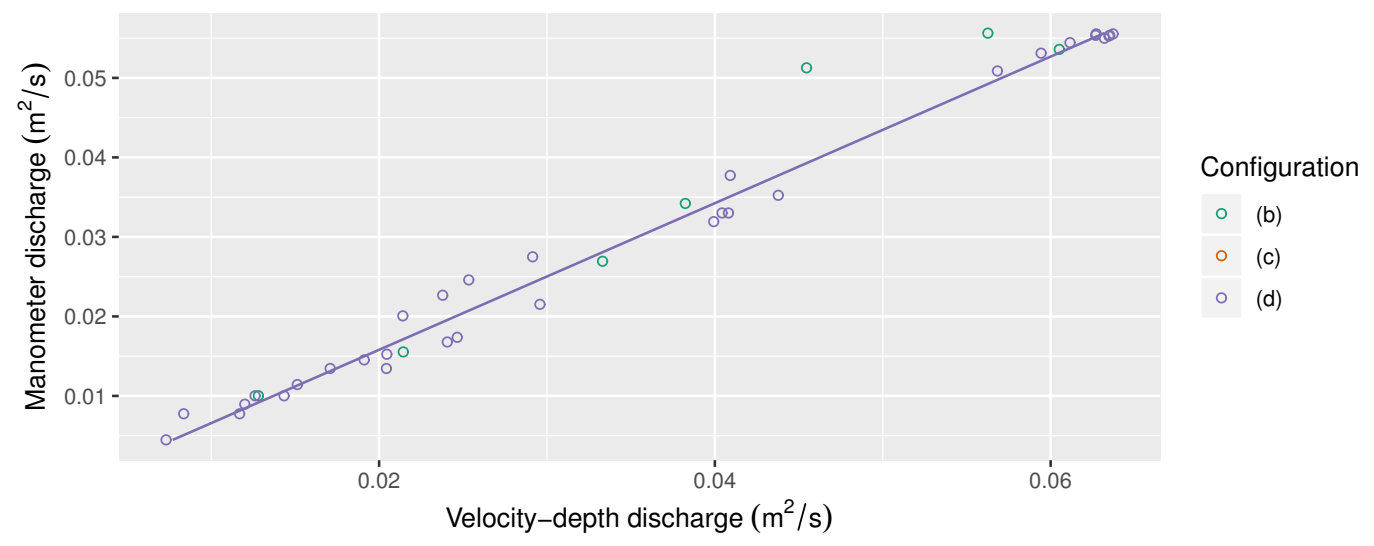

Figure 2. The relationship between velocity-depth and manometer discharges, with regression for (d).

\subsection{Numerical Model}

\subsubsection{Godunov-Type Scheme}

The governing equations are the 1D shallow water equations, a set of nonlinear, hyperbolic partial differential equations derived from the Navier-Stokes equations with the assumption that vertical acceleration is negligible [66]. They can be written in conservative form as

$$
\frac{\partial \mathbf{U}}{\partial t}+\frac{\partial \mathbf{F}}{\partial x}=\mathbf{S}
$$

where the vector of conserved variables, flux vector, and source term vector are

$$
\mathbf{U}=\left[\begin{array}{c}
h \\
h u
\end{array}\right], \mathbf{F}=\left[\begin{array}{c}
h u \\
h u^{2}+\frac{1}{2} g h^{2}
\end{array}\right] \text { and } \mathbf{S}=\left[\begin{array}{c}
0 \\
g h\left(S_{b}-S_{f}\right)
\end{array}\right],
$$

respectively, and $h$ is the water depth $(\mathrm{m}), u$ the depth-averaged velocity $(\mathrm{m} / \mathrm{s}), g$ the gravitational acceleration $\left(\mathrm{m} / \mathrm{s}^{2}\right), S_{f}$ the friction slope, and $S_{b}$ the bottom slope.

A finite volume Godunov-type scheme was chosen because it can deal with rapidly varying and transcritical flow, as well as flood waves represented as discontinuities in the water level. One splitting scheme for the inhomogeneous Equation (3) is the explicit time-marching formula

$$
\mathbf{U}_{i}^{n+1}=\mathbf{U}_{i}^{n}-\frac{\Delta t}{\Delta x}\left(\mathbf{F}_{i+1 / 2}^{n}-\mathbf{F}_{i-1 / 2}^{n}\right)+\Delta t \mathbf{S}_{i}^{n},
$$


where $\mathbf{U}_{i}^{n}$ is the average value of $\mathbf{U}$ in cell $i$ at time $t_{n}$ [66].

However, the flexible semi-discrete method is used to obtain a second-order accurate scheme. This is when the space and time discretisations are considered separately [67]. Discretisation in space but not time leads to the ordinary differential equation

$$
\frac{d \mathbf{U}_{i}}{d t}=-\frac{1}{\Delta x}\left(\mathbf{F}_{i+1 / 2}-\mathbf{F}_{i-1 / 2}\right)+\mathbf{S}_{i} .
$$

For second-order accuracy in time, a second-order Runge-Kutta method is used to solve (6) as in [68].

Let

$$
\mathbf{U}_{i}^{*}=\mathbf{U}_{i}^{n}+\Delta t K_{i}\left(\mathbf{U}_{i}^{n}\right)
$$

where

$$
K\left(\mathbf{U}_{i}^{n}\right)=-\left(\mathbf{F}_{i+1 / 2}^{n}-\mathbf{F}_{i-1 / 2}^{n}\right) / \Delta x+\mathbf{S}_{i}^{n} .
$$

This is equivalent to (5), but second-order accuracy in time is obtained with

$$
\mathbf{U}_{i}^{n+1}=\mathbf{U}_{i}^{n}+\frac{1}{2} \Delta t\left(K\left(\mathbf{U}_{i}^{n}\right)+K\left(\mathbf{U}_{i}^{*}\right)\right)
$$

instead. To use this Equation (9), the time step $\Delta t$, interface fluxes $\mathbf{F}_{i+1 / 2}^{n}$ and $\mathbf{F}_{i-1 / 2}^{n}$, and source term $\mathbf{S}_{i}^{n}$ need to be found.

For stability, each time step $\Delta t$ is obtained using the Courant-Friedrichs-Lewy condition

$$
\Delta t=C \frac{\Delta x}{\max (|u|+a)}
$$

where $a=\sqrt{g h}$ is the celerity and $C \in(0,1]$ is the Courant number [66]. The value of $C$ is fixed at the start of the simulation, although the first time step is set to be $\Delta t=10^{-5} \mathrm{~s}$. This is because, at the start of a dam break simulation, there is no contribution to the wave speed from the particle velocity $u$. However, the velocity will immediately stop being zero, and so the first time step could be so large that it leads to instabilities [67].

The HLL Riemann solver of [69] is used to estimate the flux through the cell interface. Suppose the conserved variables to the left of a given interface are $\mathbf{U}_{L}$ and those to the right are $\mathbf{U}_{R}$ as shown in Figure 3 , where $O$ is a local origin located at the cell interface. Then the flux through the interface is approximated by

$$
\mathbf{F}= \begin{cases}\mathbf{F}_{L} & \text { if } 0 \leq S_{L} \\ \frac{S_{R} \mathbf{F}_{L}-S_{L} \mathbf{F}_{R}+S_{L} S_{R}\left(\mathbf{U}_{R}-\mathbf{U}_{L}\right)}{S_{R}-S_{L}} & \text { if } S_{L} \leq 0 \leq S_{R} \\ \mathbf{F}_{R} & \text { if } S_{R} \leq 0\end{cases}
$$

where $S_{L}$ and $S_{R}$ are approximate wave speeds in the Riemann problem, estimated here using the adaptive method of [70]. In this method, an initial guess is given for the depth in the star region using a two-rarefaction approximation:

$$
h_{0}=\frac{1}{g}\left(\frac{1}{2}\left(a_{L}+a_{R}\right)+\frac{1}{4}\left(u_{L}-u_{R}\right)\right)^{2}
$$

If this depth $h_{0}$ is less than $h_{L}$ and $h_{R}$, then the two-rarefaction approximation is kept to get $h_{*}=h_{0}$. Otherwise, a two-shock approximation is used to get

$$
h_{*}=\frac{p_{L} h_{L}+p_{R} h_{R}+u_{L}-u_{R}}{p_{L}+p_{R}}
$$


where

$$
p_{K}=\sqrt{\frac{g\left(h_{0}+h_{K}\right)}{2 h_{0} h_{K}}}
$$

for $K=L, R$. Now, if $h_{*}>h_{L}$, then the left wave is a shock and

$$
S_{L}=u_{L}-a_{L} \frac{\sqrt{0.5\left(h_{*}+h_{L}\right) h_{*}}}{h_{L}},
$$

otherwise

$$
S_{L}=u_{L}-a_{L}
$$

Similarly, if $h_{*}>h_{R}$, then the right wave is a shock and

$$
S_{R}=u_{R}+a_{R} \frac{\sqrt{0.5\left(h_{*}+h_{R}\right) h_{*}}}{h_{R}},
$$

otherwise

$$
S_{R}=u_{R}+a_{R} .
$$

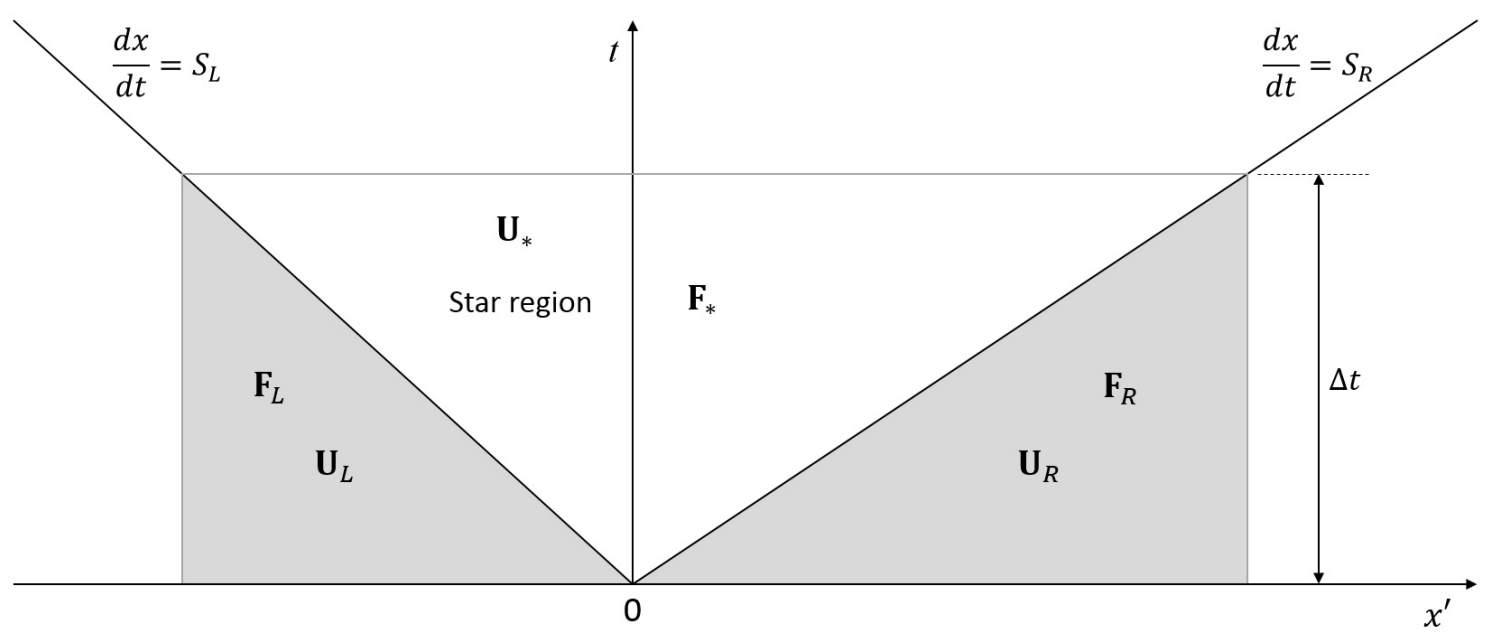

Figure 3. HLL Riemann solver of [69].

For second-order accuracy in space, the left and right Riemann states $\mathbf{U}_{L}$ and $\mathbf{U}_{R}$ are found using MUSCL-type extrapolation [71] with a minmod slope limiter as in [68]. For instance, at the interface between the $i^{\text {th }}$ and $(i+1)^{\text {th }}$ cells, the left and right Riemann states are given by

$$
\begin{aligned}
& \mathbf{U}_{i+1 / 2}^{L}=\mathbf{U}_{i}+\frac{\Delta x}{2} \nabla \mathbf{U}_{i}, \\
& \mathbf{U}_{i+1 / 2}^{R}=\mathbf{U}_{i+1}-\frac{\Delta x}{2} \nabla \mathbf{U}_{i+1}
\end{aligned}
$$

with the gradient $\nabla \mathbf{U}_{i}$ limited by

$$
\nabla \mathbf{U}_{i}=\operatorname{minmod}\left(\frac{\mathbf{U}_{i}-\mathbf{U}_{i-1}}{\Delta x}, \frac{\mathbf{U}_{i+1}-\mathbf{U}_{i}}{\Delta x}\right)
$$

where the minmod slope limiter is defined as 


$$
\operatorname{minmod}(a, b)= \begin{cases}\min (a, b) & \text { if } a, b \geq 0 \\ \max (a, b) & \text { if } a, b \leq 0 \\ 0 & \text { otherwise }\end{cases}
$$

This requires two ghost cells at each boundary.

Only the homogeneous case was taken into account when finding the flux, even though the conservation laws (3) contain source terms. This is because the bed slope source term

$$
g h S_{b}=-g h \frac{\partial z_{b}}{\partial x}
$$

is unsplit from the equations, and so is incorporated into the time-marching Formula (9) at the end of each time step. A central difference approximation gives

$$
\mathbf{S}_{i}^{n}=\left[\begin{array}{c}
0 \\
-g h_{i}^{n} \frac{z_{b,(i+1 / 2)}-z_{b,(i-1 / 2)}}{\Delta x}
\end{array}\right]
$$

as in [68]. In contrast, the friction source term $S_{f}$ is split into an ordinary differential equation

$$
\frac{d q}{d x}=-g h S_{f}
$$

solved implicitly at the start of each time step with

$$
q^{n+1}=q^{n}-\Delta \operatorname{tgh} \frac{u|u| n^{2}}{R^{4 / 3}} /\left(1+2 \Delta \operatorname{tg} \frac{|u| n^{2}}{R^{4 / 3}}\right)
$$

as in [68], where $R$ is the wetted perimeter. This is stable for high values of Manning's $n$, which is useful when comparing different ways to model leaky barriers.

\subsubsection{Leaky Barriers as Internal Boundary Conditions}

Suppose there is a leaky barrier located exactly at the interface between the cells $i$ and $i+1$, that is, at the interface $i+1 / 2$. The interface flux $\mathbf{F}_{i+1 / 2}^{n}$ needed for the time-marching Formula (9) has two components: the mass flux $h u=q$ and the momentum flux

$$
h u^{2}+\frac{1}{2} g h^{2}=\frac{q^{2}}{h}+\frac{1}{2} g h^{2} .
$$

Unless the water is shallow enough to flow unimpeded below the barrier, these fluxes cannot be found using the Riemann solver (11) - there is a leaky barrier obstructing the flow and so the shallow water Equation (3) are no longer valid. There are two steps for solving a similar problem involving a sluice gate [72]. First, find the mass flux $q$ through the hydraulic structure using a well-understood steady-state discharge equation. Second, find some depth $h$ to substitute into (27) to get the momentum flux.

However, the leaky barrier to be studied (Figure 1a) is not a well-understood hydraulic structure. The approach taken here is to assume that there are five possible operating stages for the barrier as outlined in Section 2.1. Let the depth of the base of the leaky barrier be $a_{0}$ and the top $a_{1}$, and assume that the flow is from left to right (Figure 1b). First, assume that the gate and weir are operating freely. The gate flow is given by the classical equation

$$
q_{g}=C_{g} a_{0} \sqrt{2 g h_{L}} .
$$

Here, the discharge coefficient $C_{g}$ is a function of the upstream depth $h_{L}$, 


$$
C_{g}=C_{c} \sqrt{\frac{1}{1+C_{c} a_{0} / h_{L}}}
$$

where $C_{c}$ is the contraction coefficient, as described by [72]. The weir flow is given by

$$
q_{w}=\frac{2}{3} \sqrt{2 g} C_{w}\left(h_{L}-a_{1}\right)^{3 / 2},
$$

where $C_{w}$ is a constant. Ignoring any interactions between the gate and weir, the combined flow is given by

$$
q=q_{g}+q_{w}
$$

If the gate is operating freely, then there is supercritical flow downstream of the barrier, as illustrated in stages 1 and 3 of Figure 1c. The depth of this supercritical flow, denoted $h_{\text {sup }}$, is calculated iteratively using an energy balance either side of the barrier, as in [73]. Following [72,74], if $h_{R}$ is less than the conjugate depth of $h_{\text {sup }}$, then there is sufficient momentum to push the hydraulic jump downstream and the gate is operating freely. Otherwise the gate is submerged (stages 2, 4, and 5). In these cases, the submerged flow equation of [75] is used to find a reduced value of $C_{g}$,

$$
C_{g}=K C_{c} \sqrt{1-\frac{h^{\prime}}{h_{L}}}
$$

where

$$
\frac{h^{\prime}}{h_{L}}=\frac{K^{2} \pm \sqrt{K^{4}+4 A\left(A\left(\frac{h_{R}}{a_{0}}\right)^{2}-\left(\frac{h_{L}}{a_{0}}\right) K^{2}\right)}}{2 A}
$$

and

$$
K=\frac{1}{\sqrt{1-\left(\frac{C_{c} a_{0}}{h_{L}}\right)^{2}}}, A=\frac{1}{4 C_{c}\left(1-\frac{C_{c} a_{0}}{h_{R}}\right)} .
$$

Here, the discharge coefficient $C_{g}$ is a function of $h_{R}$ as well as $h_{L}$. This is the most suitable submerged discharge equation when there are no calibration data [72,76]; however, it does add a degree of uncertainty due to its purely theoretical nature. Additionally, if $h_{R}$ is deeper than the critical depth over the weir, then the weir is also submerged (stage 5). In this case, the submerged flow equation of [77] is used to modify $q_{w}$, multiplying it by

$$
\left(1-\left(\frac{h_{R}-a_{1}}{h_{L}-a_{1}}\right)^{n}\right)^{m}
$$

where $m=0.185$ and $n=1.5$, to make $q_{w}$ also a function of $h_{R}$ as well as $h_{L}$.

The discharge Equation (31) provides the mass flux $h u=q$, which is the same leaving the left-hand cell as entering the right-hand cell. The momentum flux (27) is more difficult as it needs a value for $h$ as well as $q$, and $h$ is different in each cell due to the discontinuity created by the leaky barrier. For the momentum flux from the left-hand cell, the depth $h$ in (27) is $h_{L}$. For the flux into the right-hand cell, the depth $h$ in (27) is $h_{\text {sup }}$ for stages 1 and 3 , and $h_{R}$ for stages 2,4 , and 5 .

\subsubsection{Establishing Discharge Coefficients and Energy Losses}

The internal boundary condition used in the 1D model is based on equations with empirical parameters in Supplementary Materials. These parameters were found by analysing the measured depths immediately upstream and downstream of the barrier. First, as the slots either side of the barrier reduced the barrier width to $0.264 \mathrm{~m}$, the discharge Equation (31) was multiplied by the ratio 
$0.246 / 0.294 \approx 0.84$. The discharge equation requires two more coefficients: the gate contraction coefficient $C_{c}$ and the weir discharge coefficient $C_{w}$. For each of the 52 free-flow experiments, the depth measurements $h_{11}$ were plugged into the discharge equation, with this predicted discharge then visually compared against the measured discharge as in Figure 4 . The coefficients $C_{c}=0.70$ and $C_{w}=0.70$ were found to give the best fit with the measurements, and so they were used in the numerical model.

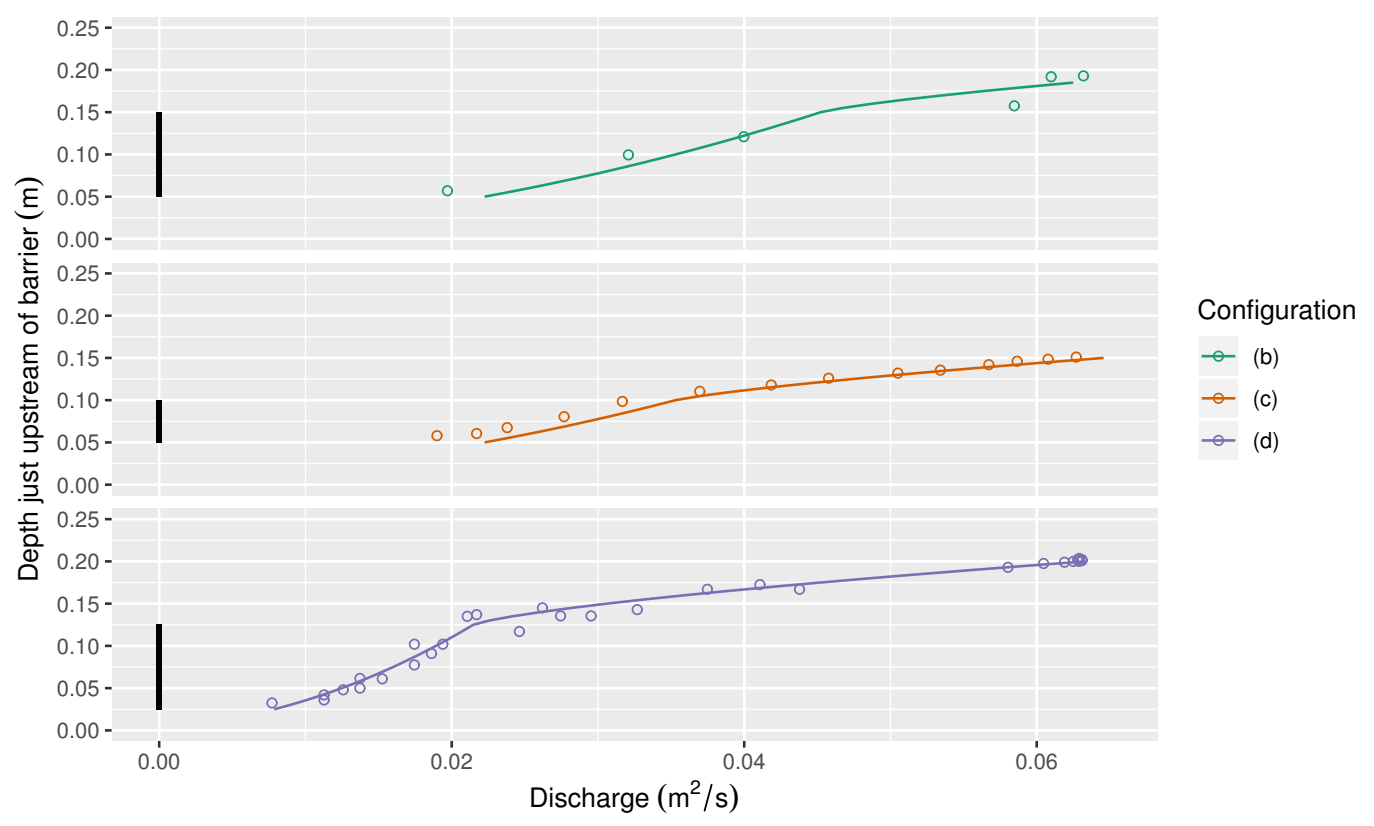

Figure 4. Measured depth-discharge relationship (circles) and the empirical discharge equation with $C_{c}=0.70$ and $C_{w}=0.70$ (lines) for each barrier configuration. Only includes free-flow scenarios where the depth is greater than the gap underneath the barrier.

Second, in free-flow conditions, an energy balance is required to find the depth of the supercritical flow downstream of the leaky barrier, $h_{\text {sup }}$. Bernoulli's equation gives

$$
h_{L}+\frac{\left(q / h_{L}\right)^{2}}{2 g}=h_{\text {sup }}+\frac{\left(q / h_{\text {sup }}\right)^{2}}{2 g}+\Delta E .
$$

Note that the change in the channel bed elevation $\Delta z_{b}$ is not included in (36) since we are considering values at the cell interface $i+1 / 2$. The effect of the bed slope is taken into account in the source term.

If we ignore energy loss (i.e., assume $\Delta E=0$ ) and solve (36) iteratively for $h_{\text {sup }}$, the water exits the leaky barrier too quickly in the 1D model, resulting in the hydraulic jump occurring further downstream than observed. However, the upstream backwater effect is captured well, indicating that the problem is not in the value of $q$, which determines the mass flux. This is demonstrated in Figures A1-A8 in the Appendix A. Therefore, a method for estimating $\Delta E$ in (36) was required. Incorporating energy losses into the momentum flux like this is reported elsewhere in the literature, for example, for 1D flow around islands [78].

To find a function for these energy losses, they were first approximated for each of the 52 free-flow experiments using Bernoulli's equation:

$$
\Delta E=h_{u s}+\frac{\left(q / h_{u s}\right)^{2}}{2 g}-h_{d s}-\frac{\left(q / h_{d s}\right)^{2}}{2 g}-\Delta z_{b}
$$

where $q$ is the measured discharge, $h_{u s}$ is the depth measurement $h_{11}$, and $h_{d s}$ is a depth measurement downstream of the leaky barrier, generally $h_{12}$. In some cases $h_{d s}$ was taken to be $h_{11.15}$ or $h_{11.30}$ instead, 
depending on the position of the hydraulic jump and weir nappe. Note that $\Delta z_{b}$ is included in (37) because the depth measurements were taken up to $0.3 \mathrm{~m}$ away from each other. This analysis resulted in the regression equation

$$
\Delta E=0.012-0.362 \cdot a_{0}+0.205 \cdot h_{u s}
$$

which gave $R^{2}=0.48$, plotted in Figure 5 . This is included in the 1D model by replacing $h_{u s}$ with $h_{L}$ in (38), and then plugging $\Delta E$ into (36) when finding the supercritical depth $h_{\text {sup }}$.

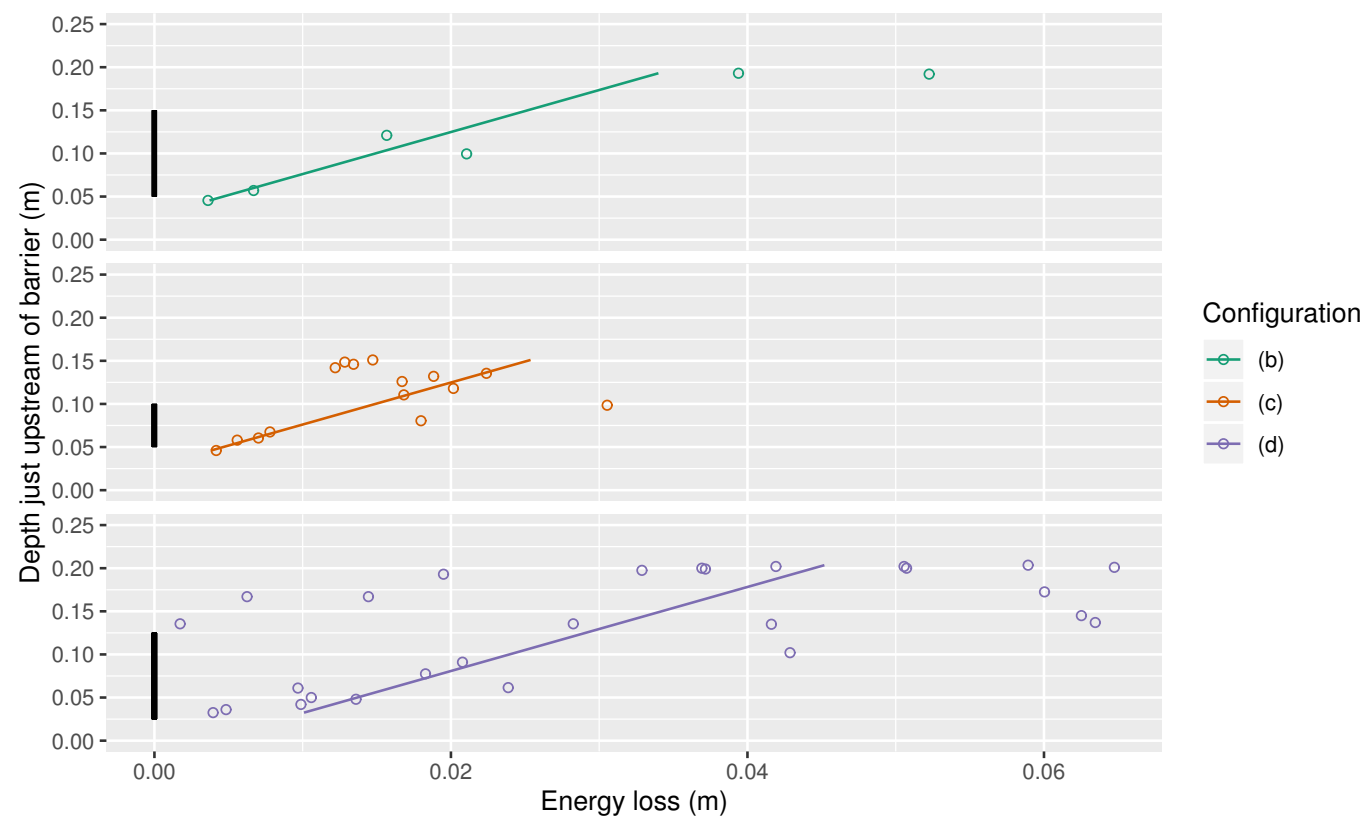

Figure 5. Estimated measured energy losses (circles) and the regression Equation (38) (lines) for each barrier configuration. Only includes free-flow scenarios where the depth is greater than the gap underneath the barrier.

\section{Results}

\subsection{Benchmark Tests}

The 1D scheme without a leaky barrier was tested to check if it correctly solved the shallow water Equation (3). These benchmarks included two steady-state and one transient case. Then the 1D scheme with a leaky barrier operating as a sluice gate (stages 1 and 2) was tested against three further benchmarks. Unless otherwise noted, a Courant number of $C=1.0$ was used.

\subsubsection{Subcritical Flow}

To verify that the scheme can deal with topographical variations, the first benchmark was steady-state subcritical flow over a bump [79]. Here, the domain of length $l=25 \mathrm{~m}$ has its bed given by

$$
z_{b}(x)= \begin{cases}0.2-0.05(x-10)^{2} & \text { if } 8<x<12 \\ 0 & \text { otherwise }\end{cases}
$$

with the upstream boundary condition $q(0)=4.42 \mathrm{~m}^{2} / \mathrm{s}$ and downstream boundary condition $h(25)=2 \mathrm{~m}$. The initial conditions are set to be $q(x)=4.42 \mathrm{~m}^{2} / \mathrm{s}$ and $h(x)=2 \mathrm{~m}$ everywhere, and Figure 6 shows that they settle out to the correct steady state. 

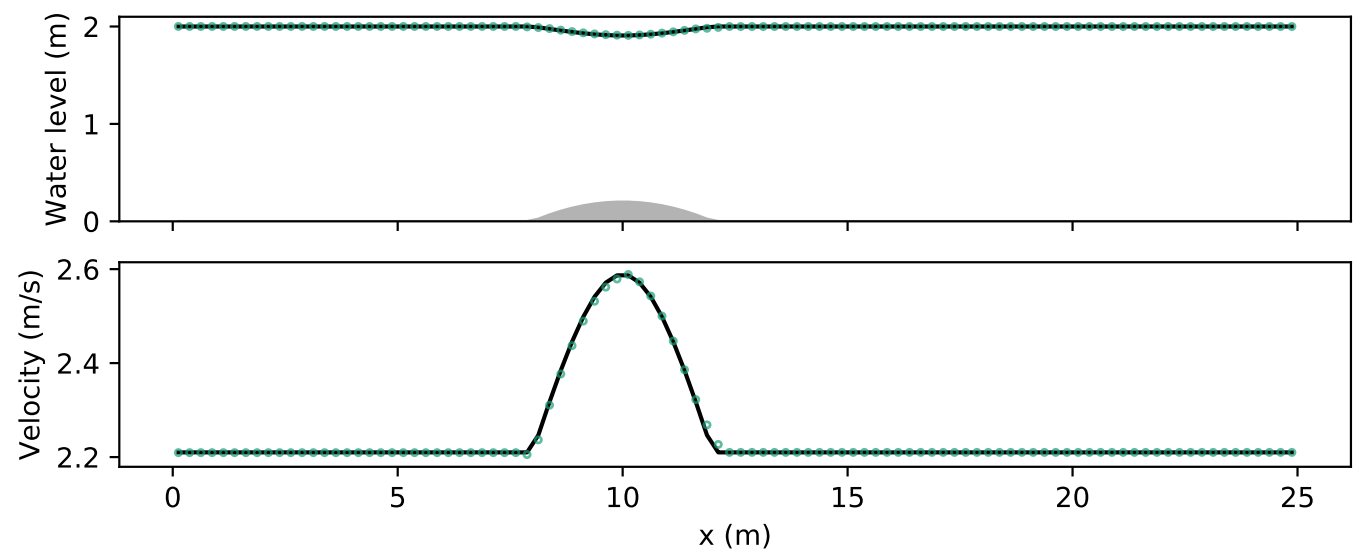

Figure 6. Analytical (black lines) and numerical (green circles) solution for subcritical flow.

\subsubsection{Transcritical Flow}

To verify that the scheme can deal with transcritical flows and friction represented by Manning's $n$, the second benchmark was a steady-state transcritical flow case from [79]. Full derivations of the benchmark can be found in [80] and a programmed example in [81]. Figure 7 shows that, when the simulation settles to a steady state, there is only a small error in the location of the hydraulic jump.
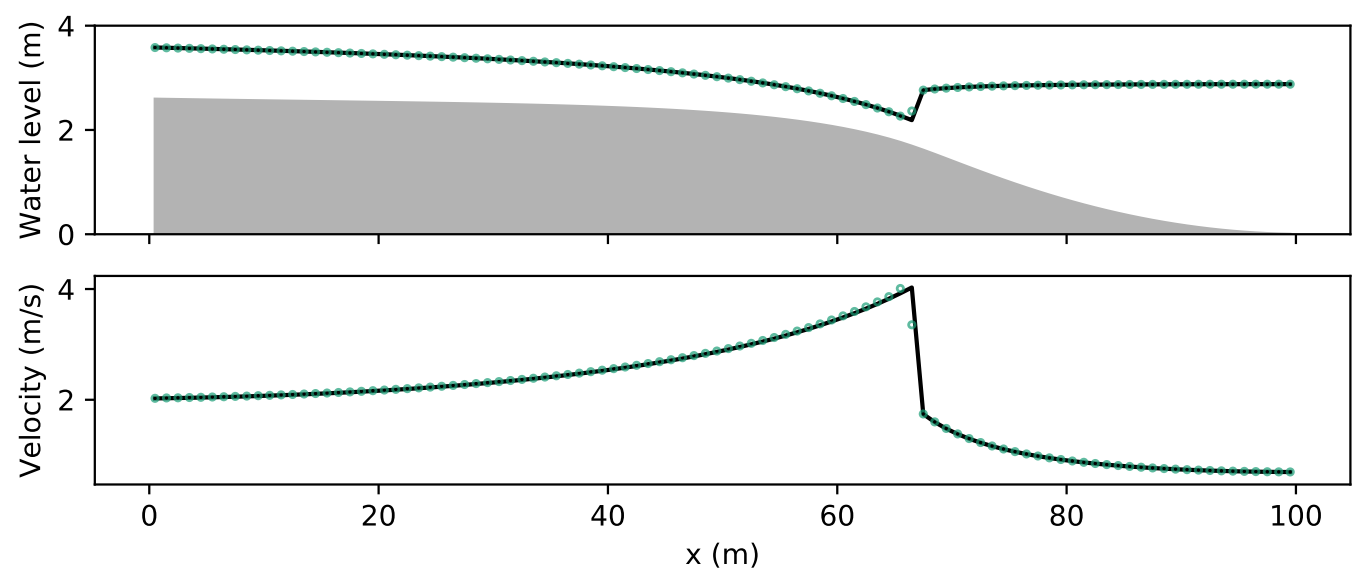

Figure 7. Analytical (black lines) and numerical (green circles) solution for transcritical flow.

\subsubsection{Riemann Problem}

To verify that the scheme can capture shocks, the third benchmark was a Riemann problem from [66], with discontinuous initial conditions

$$
h(x)=\left\{\begin{array}{ll}
1.0 & \text { if } x<40 \\
0.1 & \text { otherwise }
\end{array} \text { and } q(x)= \begin{cases}2.5 & \text { if } x<40 \\
0.0 & \text { otherwise }\end{cases}\right.
$$

across a domain of length $l=80 \mathrm{~m}$. The analytical solution involves a left transcritical rarefaction and right shock, and Figure 8 shows that it is recreated well. 

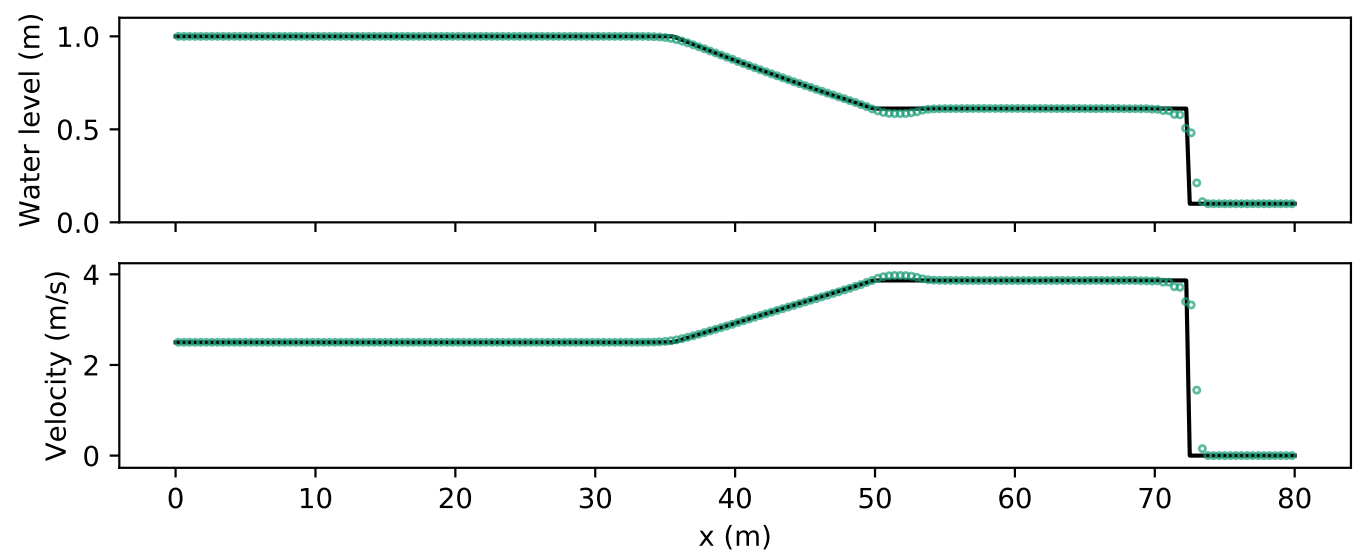

Figure 8. Analytical (black lines) and numerical (green circles) solution for Riemann problem.

\subsubsection{Sluice Gate Riemann Problems}

The internal boundary condition presented in Section 2.3.2 generalises the numerical method of [72]. In the same paper [72], analytical solutions to Riemann problems where a sluice gate separates the two Riemann states were also derived. As the leaky barrier can operate as a sluice gate (stage 1 and 2), these benchmarks were used to test the 1D model. In all three cases, the gap under the barrier was set to be $a_{0}=0.2 \mathrm{~m}$. The initial conditions for discharge were set to be $q(x)=0$ everywhere and the depth set to be

$$
h(x)= \begin{cases}1.0 & \text { if } x<50 \\ h_{R} & \text { otherwise }\end{cases}
$$

where $h_{R}=0.002,0.2,0.6 \mathrm{~m}$ for each case respectively.

Figure 9 shows that the wave structure, speeds, and strengths are accurate in all three wet-bed cases, but the first test case requires a smaller Courant number to obtain accurate results. This demonstrates the shock-capturing capabilities of the scheme under transient conditions when leaky barriers are included.

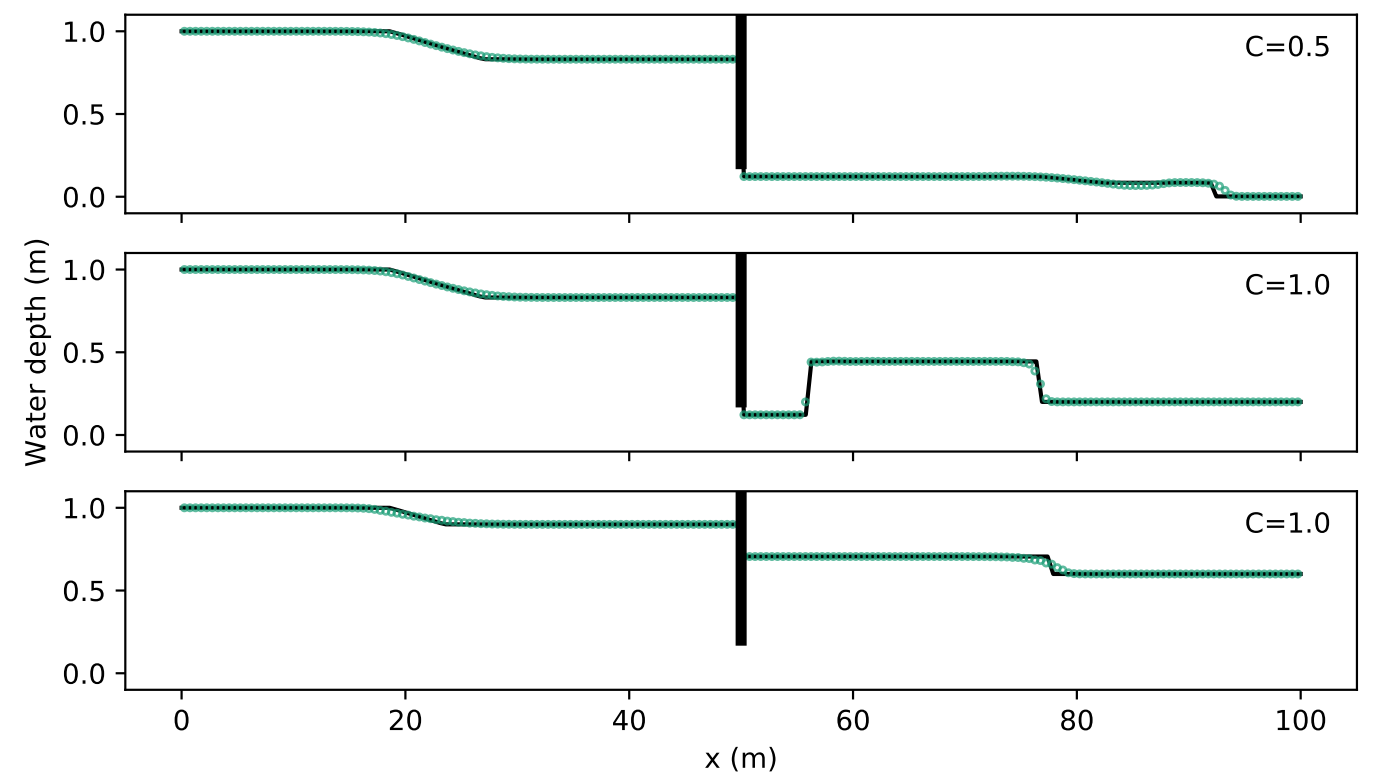

Figure 9. Analytical (black lines) and numerical (green circles) solutions for wet-bed Riemann problems at sluice gates, based on Tests 3-5 from [72] with $C_{c}=0.61$ and $\Delta E=0$. 


\subsection{Steady-State Flume Experiments}

The 1D model should be able to recreate longitudinal profiles for each of the 55 steady-state flume scenarios. This was tested by using the parameters from Section 2.3.3 for the internal boundary condition, the measured discharge as an upstream boundary condition, and the depth measurement $h_{17.8}$ as a downstream boundary condition. As the grid size was set to be $\Delta x=0.1$, the leaky barrier was located at $x=11.1 \mathrm{~m}$, four centimetres away from its real placement. The Courant number was set to be $C=1.0$ and the model run until it reached a steady state.

The water surface profiles of eight representative examples are displayed in Figure 10, with full results in Figures A1-A8 in the Appendix A. First recall that the internal boundary condition introduces two new pieces of information into the domain: the discharge through the barrier and the supercritical depth downstream of the barrier. The first piece of information travels both upstream and downstream from the barrier, whereas the second piece of information travels only downstream from the barrier. Generally, the profile upstream of the barrier is simulated well by the model, reflecting the lack of scatter in the discharge equation shown in Figure 4. The profile downstream of the barrier is subject to more error, reflecting the poor $R^{2}$ value for the $\Delta E$ Equation (38) and the resulting scatter in Figure 5. Despite this scatter, the downstream profile is still captured accurately by the model in most cases. Moreover, as there were no velocity measurements across the flume, the location of the hydraulic jump is a proxy for the velocity. Its accurate placement thus suggests that the model accurately simulates the velocities.

It is interesting to note that the submerged states are recreated well, considering that the two parameters of (31) were calibrated for the free-flow conditions, and it is only the equations of [75] and [77] that were used to generalise these to submerged flow. This is important because leaky barriers are installed in series, and so the backwater effect from a downstream barrier may influence the hydraulics of an upstream barrier.

\subsection{Transient Flume Experiments}

Finally, to demonstrate the transient functionality of the 1D model, it was used to simulate a dam break in the flume for each configuration (a)-(d). The initial conditions were

$$
h(x)= \begin{cases}0.20 & \text { if } x<8 \\ 0.02 & \text { otherwise }\end{cases}
$$

with an upstream boundary condition of $q=0.06 \mathrm{~m}^{2} / \mathrm{s}$. The results, shown in Figure 11, are similar to video footage from the flume experiments. However, there is currently no quantitative data to compare them against. Nonetheless, the hydrographs in Figure 12 show that the bigger barriers provide more of an obstruction, which is to be expected. 

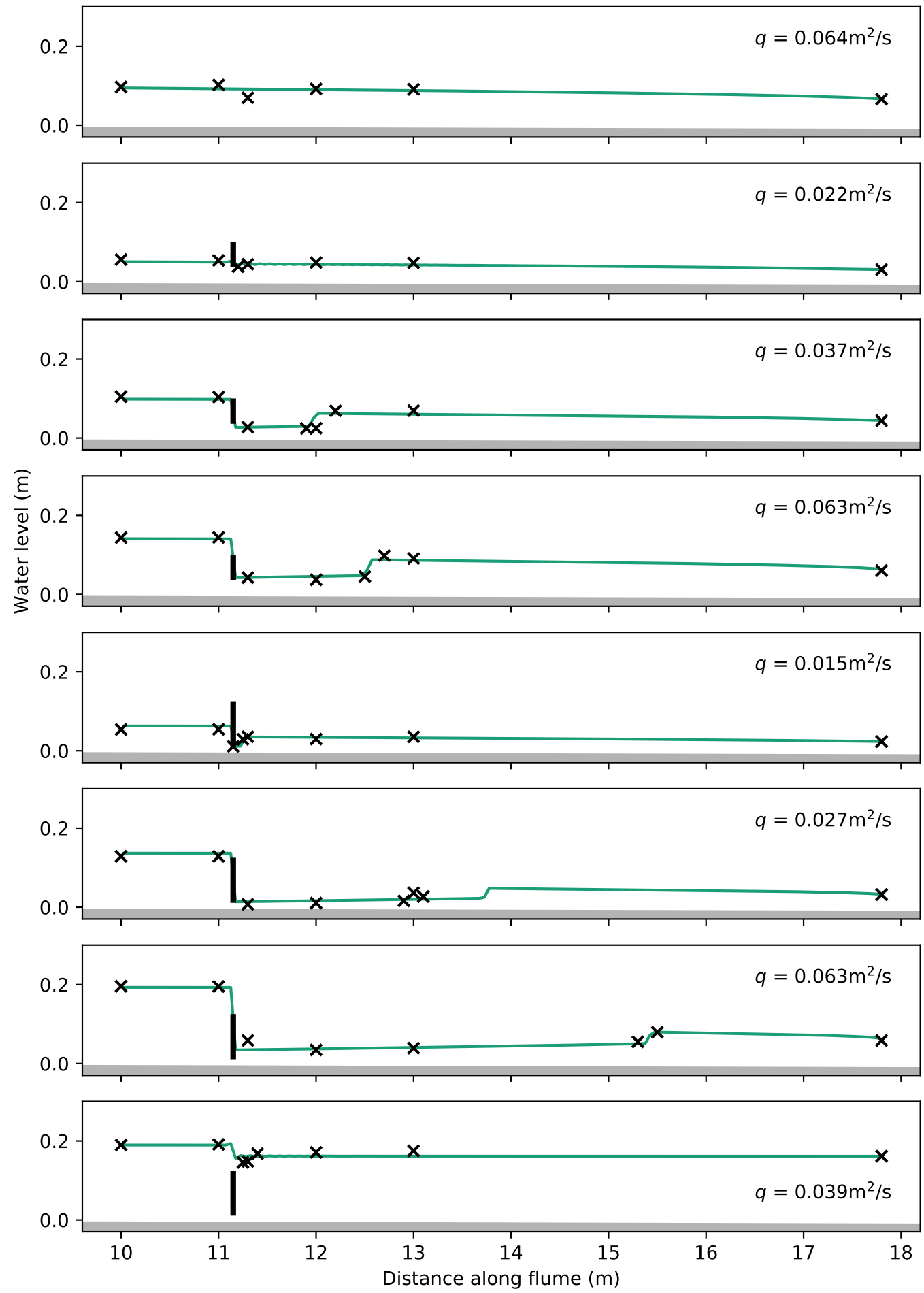

Figure 10. Numerical solutions (green lines) and observations (black crosses) for eight representative steady-state experiments in the flume. Note that the weir overflow is squeezed into the leaky barrier cell interface, so it is modelled even though it is not plotted. 

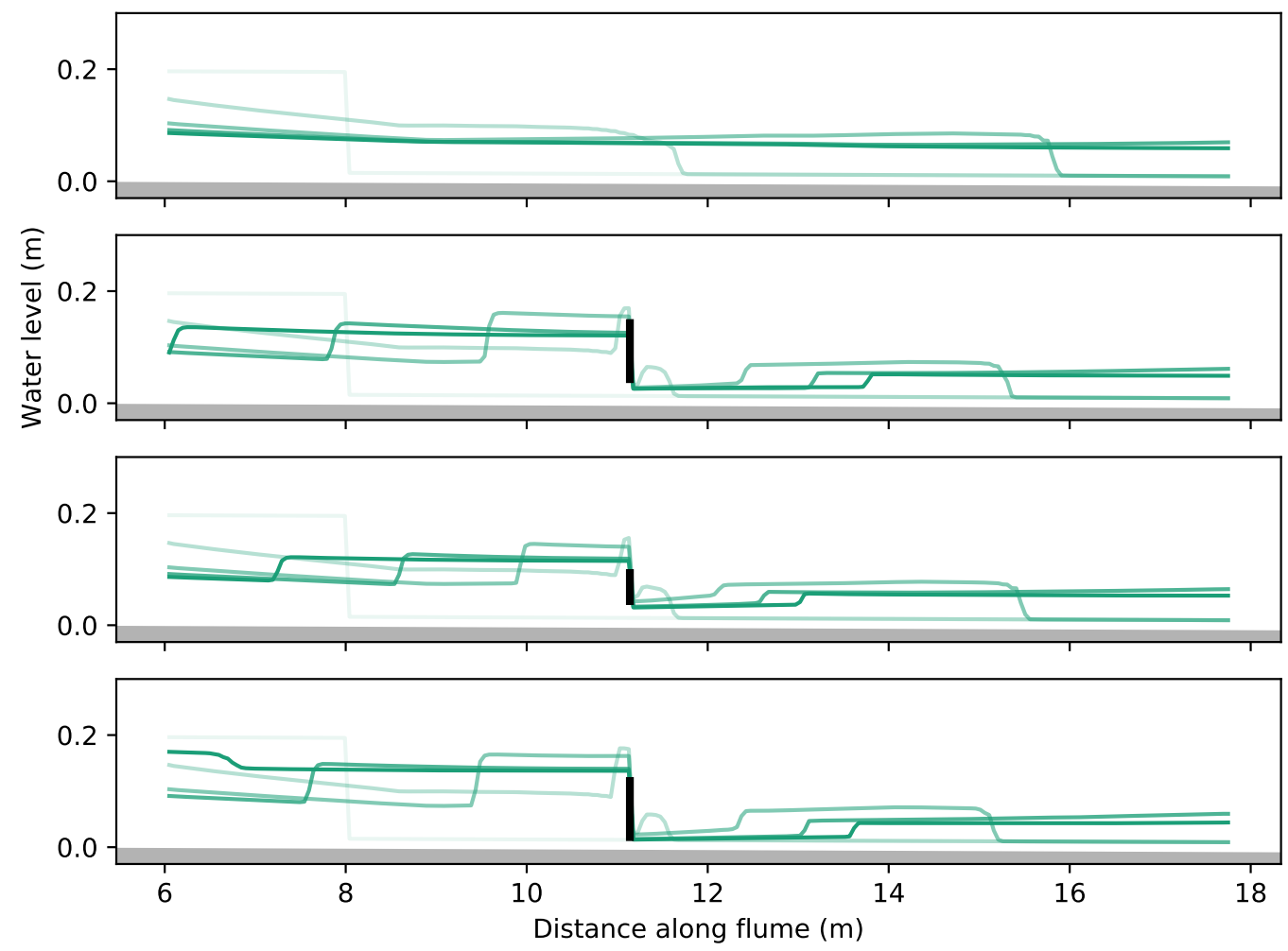

Figure 11. Longitudinal profiles at $t=0.0,1.4,2.8,4.2,5.6,7.0 \mathrm{~s}$ for the dam break simulations for configurations (a)-(d).

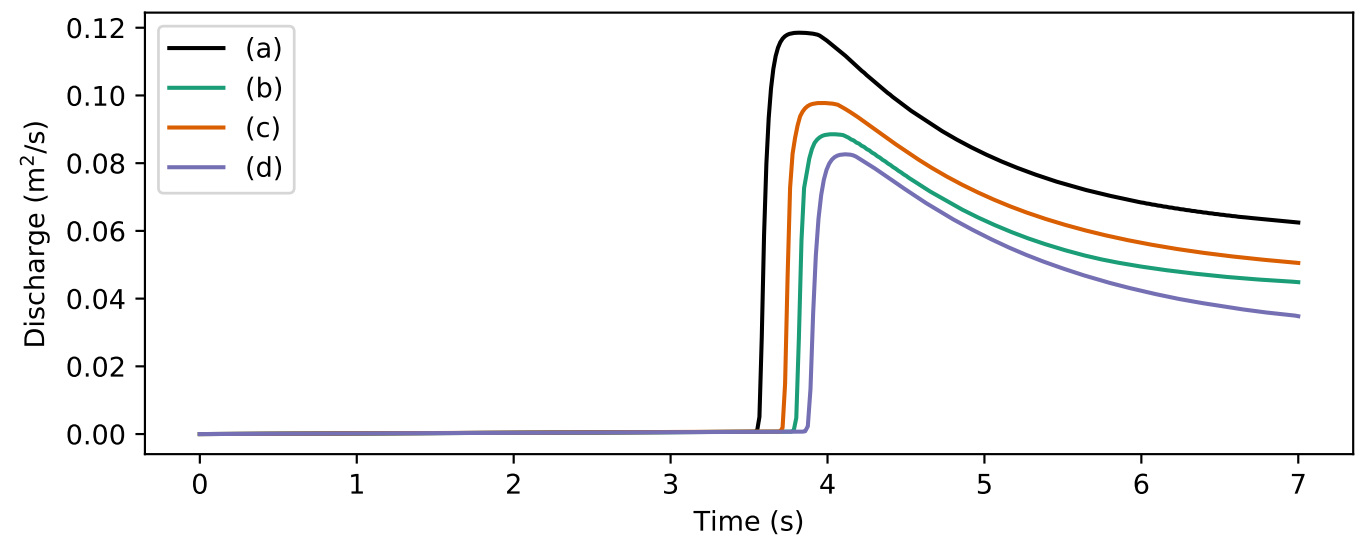

Figure 12. Flood hydrograph at $x=16 \mathrm{~m}$ for the dam break simulations for configurations (a)-(d).

\section{Discussion}

Despite being a popular nature-based solution, the leaky barrier is currently not well-understood. As the behaviour of individual barriers is generally unknown, inserting them into hydrological and hydraulic models involves inherent uncertainties, and so the results of these larger scale models have limitations. To address these evidence gaps, the present study tested a newly developed 1D hydraulic model with experimental flume data. The results suggest that representing leaky barriers as hydraulic structures is a valid method, provided that the barrier resembles the hydraulic structure, the energy losses are incorporated into the momentum part of the internal boundary condition, and possible submergence from downstream backwaters is considered. In particular, this investigation of the 
hydraulic structure method addresses a specific research gap put forward in a recent review paper on modelling leaky barriers [56]. Given the current interest discussed above in installing multiple leaky barriers across catchments for flood prevention purposes, greater understanding of potential synchronisation issues is critical. The model presented here, which provides a first approximation of a range of natural and designed barrier types including log jams, woody debris and beaver dams, has the potential to address this issue by putting a large number of leaky barriers into a $1 \mathrm{D}$ hydrodynamic model of a channel network.

More generally, the approach taken in this study, using a combination of physical and mathematical modelling, has great potential to answer questions which urgently need addressing, as highlighted in the introduction to this paper. Further work is currently being undertaken to take this forwards, involving further flume experiments, 1D modelling, and 2D and 3D computational fluid dynamics (CFD) simulations. For leaky barrier designs where empirical equations already exist, such as the letterbox slot design [59] which can be modelled as a large rectangular orifice with weir overflow, the approach presented here can be applied directly. However, some barrier designs do not resemble hydraulic structures with established equations (e.g., combinations of gates, weirs and orifices). Thus further research is needed to establish discharge equations. To this end, further flume experiments are being undertaken alongside CFD simulations. CFD provides a virtual hydraulic flume, allowing a greater range of barrier designs to be investigated, including under transient conditions, and will generate much greater understanding of hydraulic behaviour. The CFD models will be tested and validated using the experimental data. The results of this work will in turn be used to inform and validate 1D models for a variety of barrier designs. Ultimately these will be applied to assess the performance of networks of barriers under transient flood conditions.

\section{Conclusions}

This study set out a methodology for developing mathematical models that both capture the hydraulics of individual leaky barriers accurately and can be applied to networks of barriers across a catchment. The method was tested for a simple leaky barrier, with the 1D hydraulic modelling results comparable to those from a controlled hydraulic flume. Further work is being undertaken so that the method can be applied to more complex leaky barriers. This will answer key questions about the optimal leakiness of small-scale interventions, the limits to their usefulness, and possible synchronisation problems when the effect of multiple barriers is aggregated.

Supplementary Materials: The 1D model code and the flume data are openly available from the Newcastle University research data repository at http:/ / doi.org/10.25405/data.ncl.11499159.

Author Contributions: Conceptualization, C.J.M.H.; methodology, S.L. and V.G.; formal analysis, S.L.; investigation, S.L. and C.J.M.H.; data curation, S.L.; writing-original draft preparation, S.L. and C.J.M.H.; writing-review and editing, C.J.M.H. and S.L.; visualization, S.L.; supervision, C.J.M.H., V.G. and P.F.Q.; funding acquisition, C.J.M.H. All authors have read and agreed to the published version of the manuscript.

Funding: This research was funded by the Engineering and Physical Sciences Research Council grant number $\mathrm{EP} / \mathrm{R} 51309 \mathrm{X} / 1$.

Acknowledgments: The authors would like to thank Oscar Ryans for assisting with the flume experiments, and the two anonymous reviewers for their feedback.

Conflicts of Interest: The authors declare no conflict of interest.

\section{Appendix A}

The full 55 results for Section 3.2 are given in this appendix. These comprise all four configurations (a)-(d). The graphs display the observations (black crosses), simulations without energy losses (dotted blue line), and simulations with energy losses (solid blue line). 


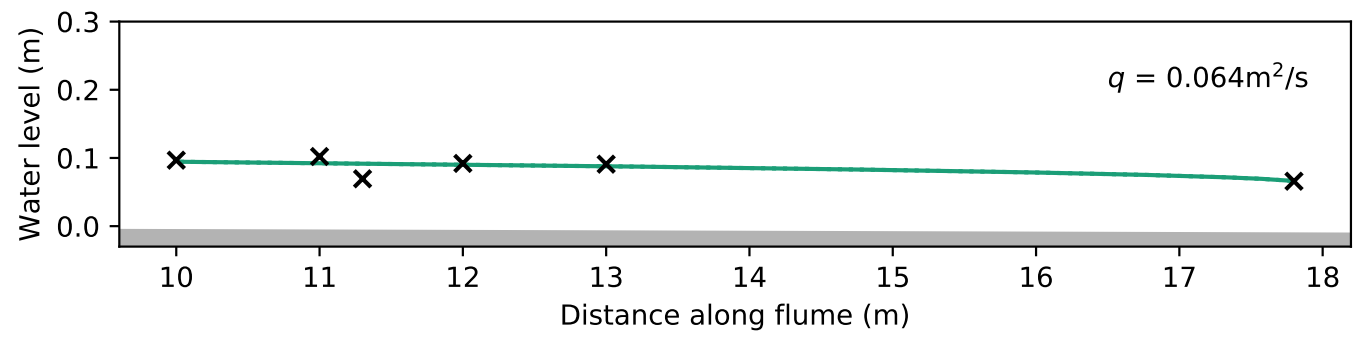

Figure A1. Results for configuration (a).
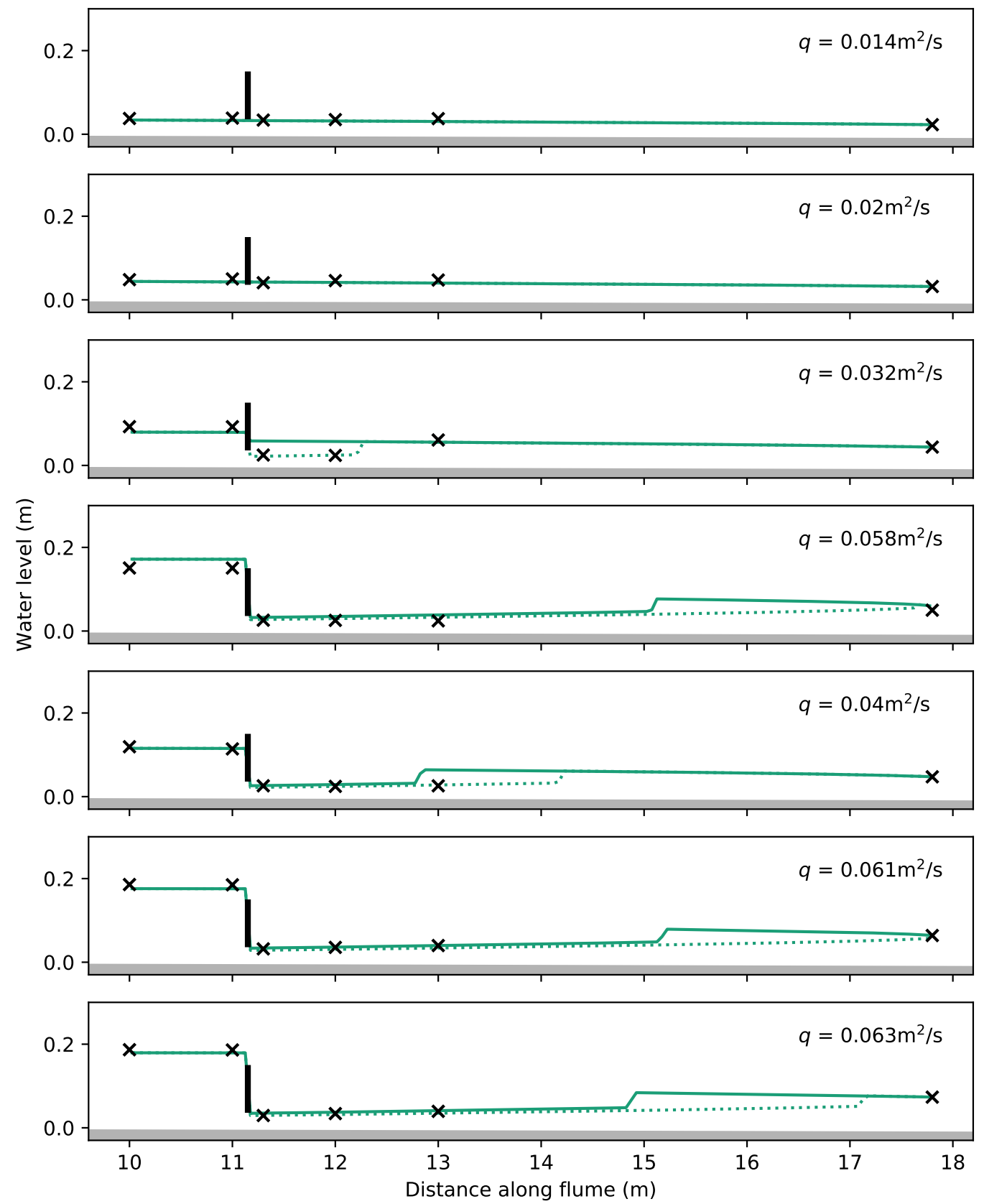

Figure A2. Results for configuration (b). 

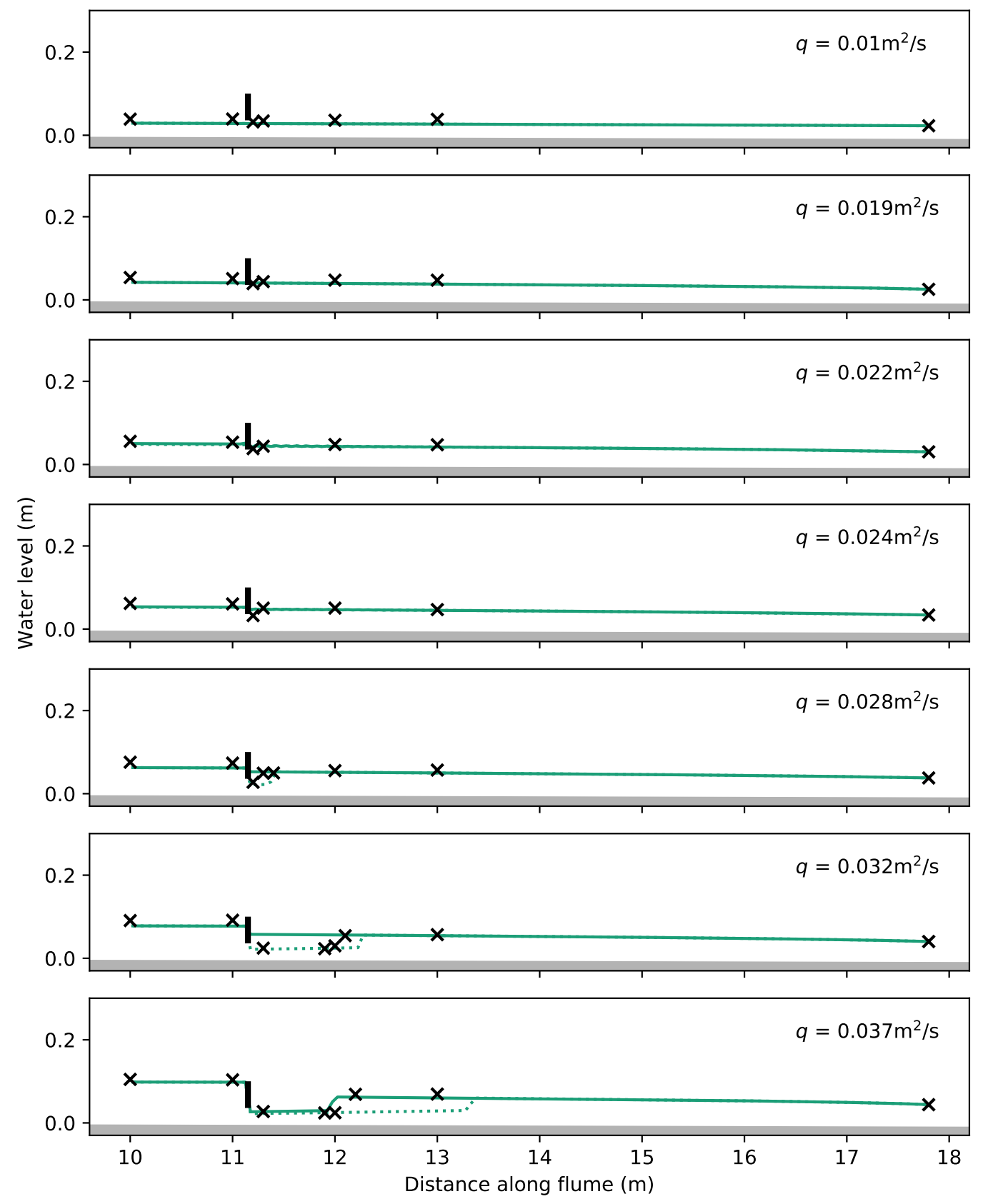

Figure A3. Results for configuration (c). 

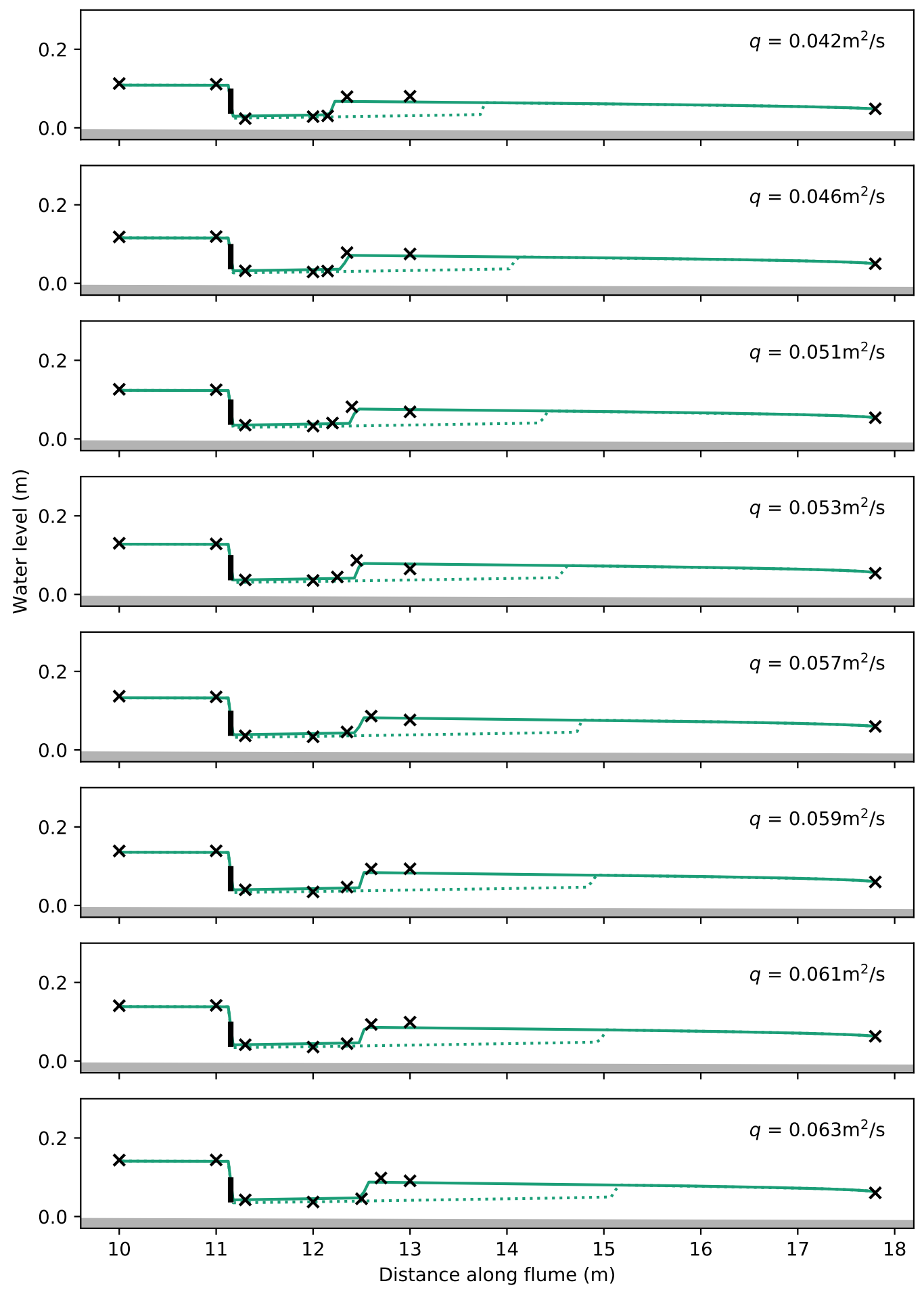

Figure A4. Results for configuration (c). 

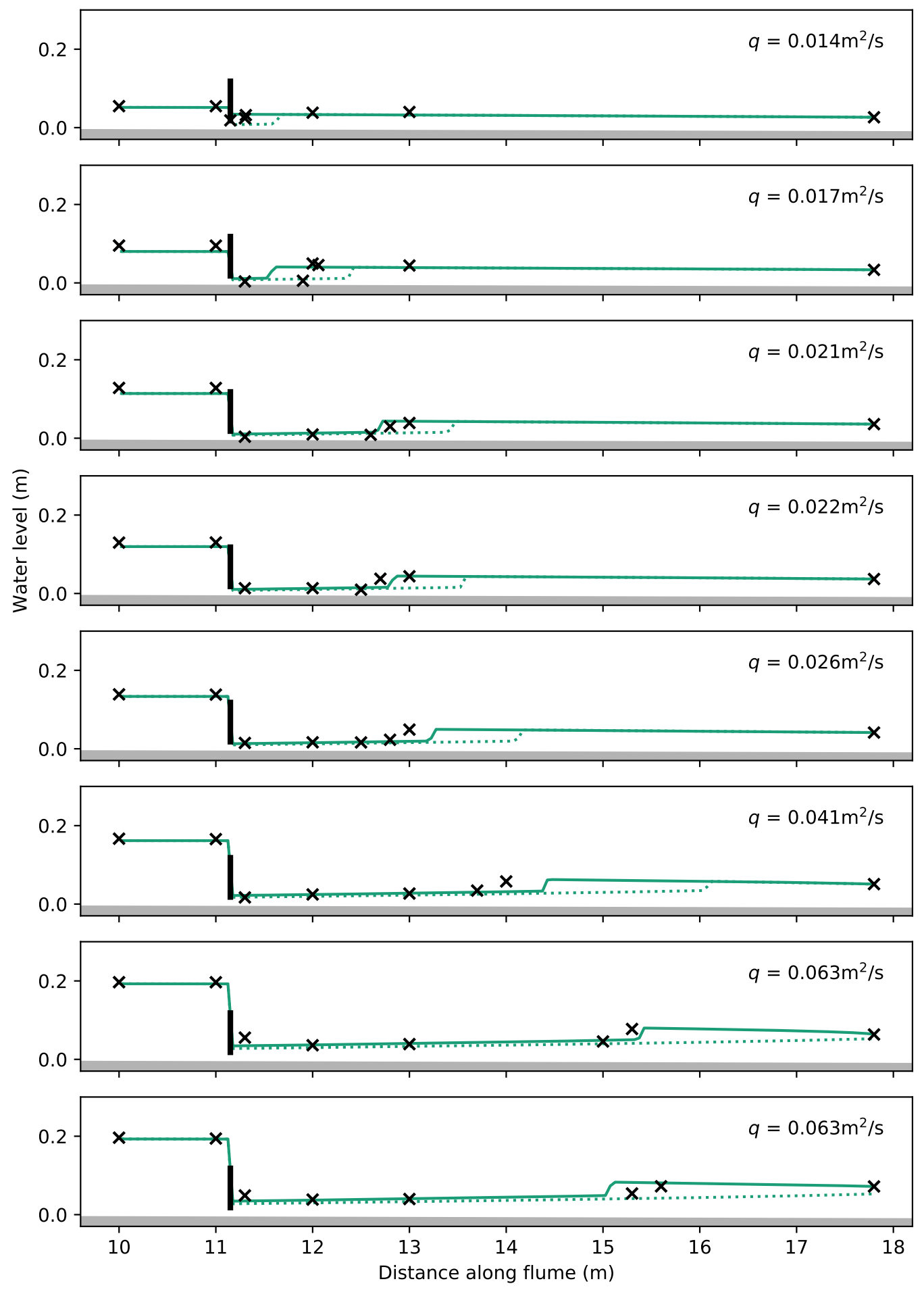

Figure A5. Results for configuration (d). 

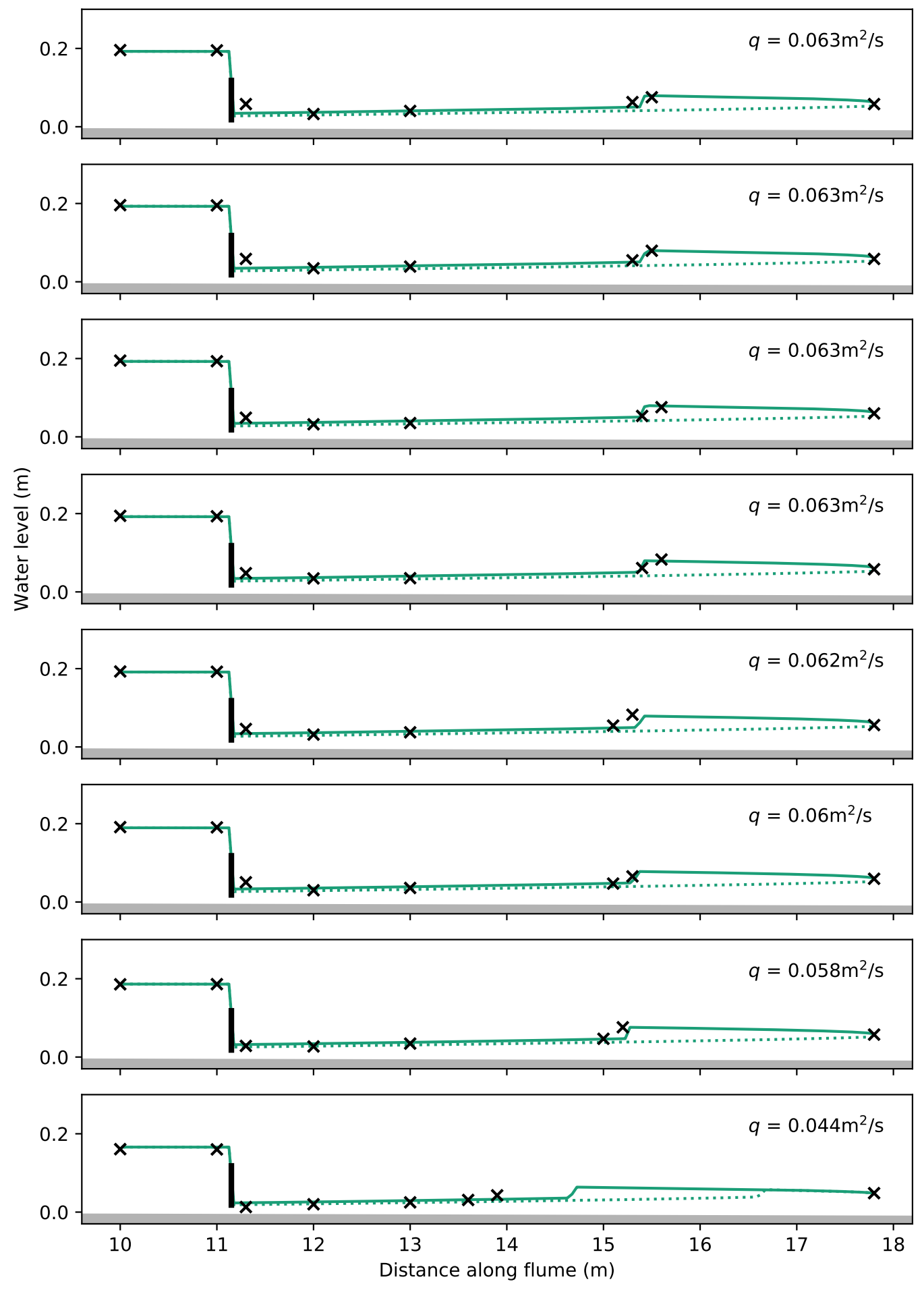

Figure A6. Results for configuration (d). 

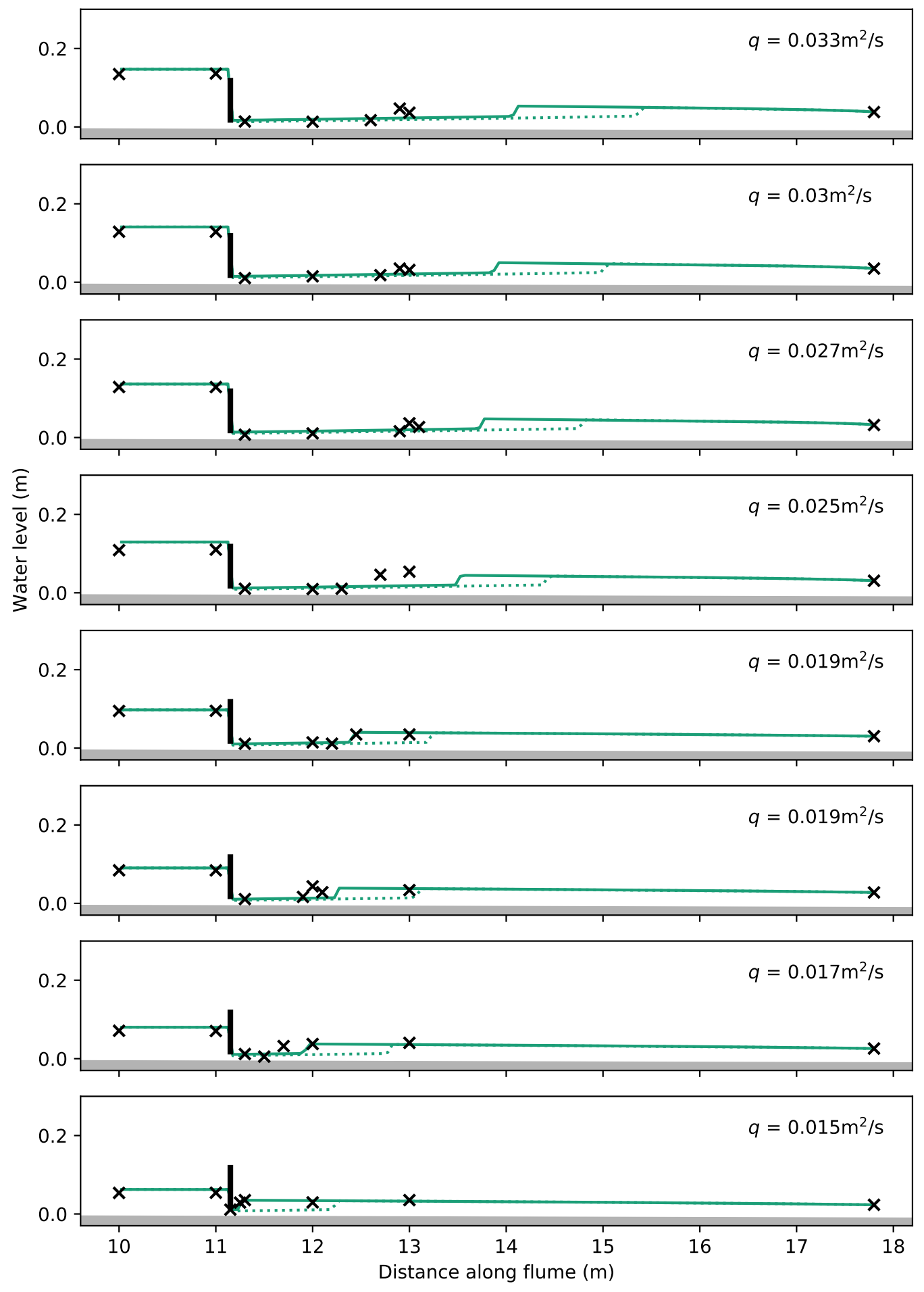

Figure A7. Results for configuration (d). 

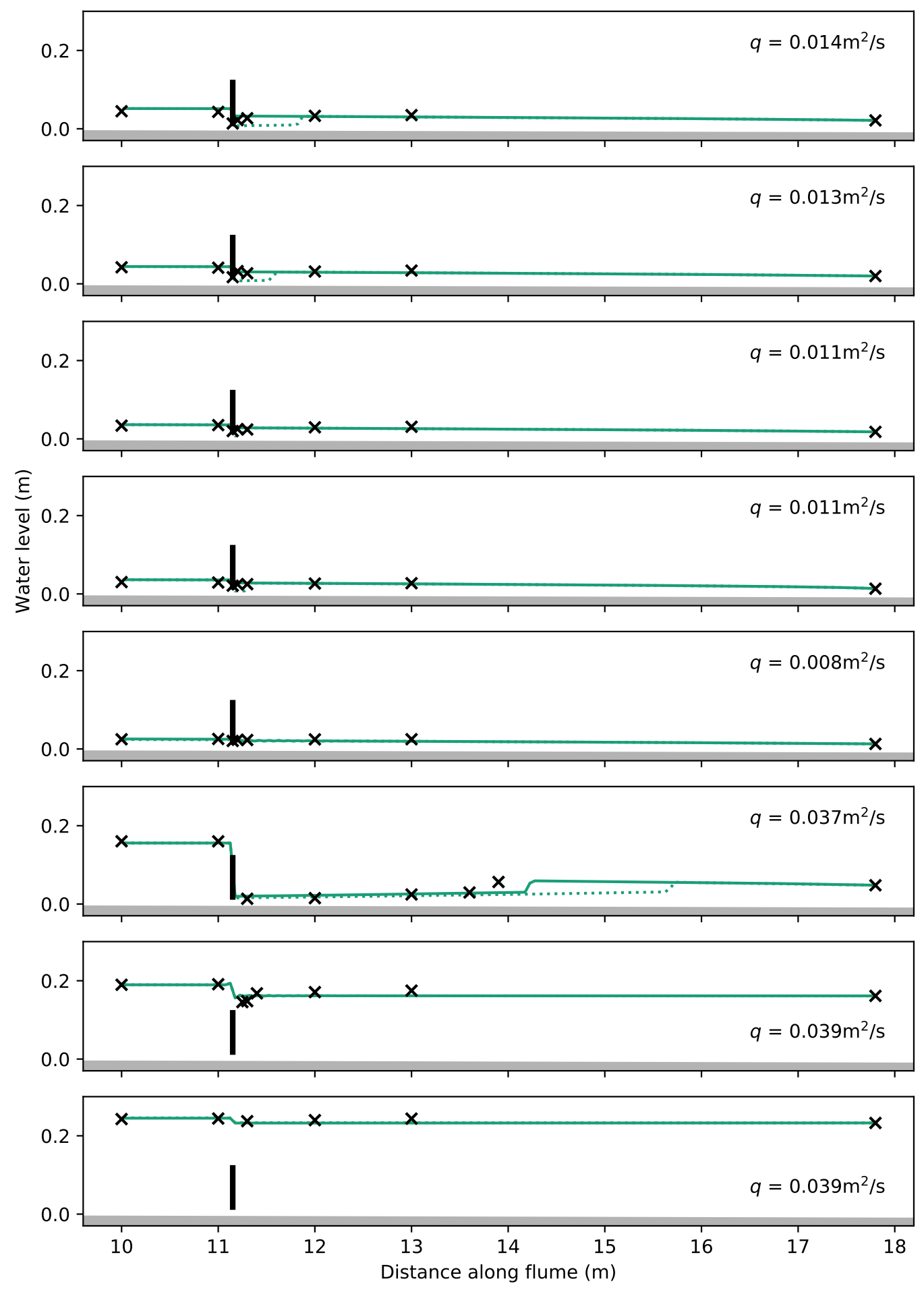

Figure A8. Results for configuration (d).

\section{References}

1. Arnell, N.; Gosling, S. The impacts of climate change on river flood risk at the global scale. Clim. Chang. 2016, 134, 387-401. [CrossRef]

2. Dadson, S.J.; Hall, J.W.; Murgatroyd, A.; Acreman, M.; Bates, P.; Beven, K.; Heathwaite, L.; Holden, J.; Holman, I.P.; Lane, S.; et al. A restatement of the natural science evidence concerning catchment-based 'natural' flood management in the UK. Proc. R. Soc. A-Math. Phys. 2017, 473. [CrossRef] [PubMed] 
3. Chiverrell, R.C.; Sear, D.A.; Warburton, J.; Macdonald, N.; Schillereff, D.N.; Dearing, J.A.; Croudace, I.W.; Brown, J.; Bradley, J. Using lake sediment archives to improve understanding of flood magnitude and frequency: Recent extreme flooding in northwest UK. Earth Surf. Process. Landf. 2019, 44, 2366-2376. [CrossRef]

4. Jacobson, C.R. Identification and quantification of the hydrological impacts of imperviousness in urban catchments: A review. J. Environ. Manag. 2011, 92, 1438-1448. [CrossRef] [PubMed]

5. Hewett, C.J.; Quinn, P.F.; Wilkinson, M.E. The decision support matrix (DSM) approach to reducing environmental risk in farmed landscapes. Agric. Water Manag. 2016, 172, 74-82. [CrossRef]

6. Grigg, D.B. The Agricultural Systems of the World: An Evolutionary Approach; Cambridge Geographical Studies; Cambridge University Press: Cambridge, UK, 1974.

7. Ramankutty, N.; Foley, J.A. Estimating historical changes in global land cover: Croplands from 1700 to 1992. Glob. Biogeochem. Cycles 1999, 13, 997-1027. [CrossRef]

8. Goldewijk, K.K. Estimating Global Land Use Change over the Past 300 Years: The HYDE Database. Glob. Biogeochem. Cycles 2001, 15, 417-433. [CrossRef]

9. O'Connell, E.; Ewen, J.; O'Donnell, G.; Quinn, P. Is there a link between agricultural land-use management and flooding? Hydrol. Earth Syst. Sci. 2007, 11, 96-107. [CrossRef]

10. Kendon, E.J.; Roberts, N.M.; Fowler, H.J.; Roberts, M.J.; Chan, S.C.; Senior, C.A. Heavier summer downpours with climate change revealed by weather forecast resolution model. Nat. Clim. Chang. 2014, 4, 570. [CrossRef]

11. Forzieri, G.; Feyen, L.; Russo, S.; Vousdoukas, M.; Alfieri, L.; Outten, S.; Migliavacca, M.; Bianchi, A.; Rojas, R.; Cid, A. Multi-hazard assessment in Europe under climate change. Clim. Chang. 2016, 137, 105-119. [CrossRef]

12. Mitsch, W. Ecological Engineering: A New Paradigm for Engineers and Ecologists in Engineering within Ecological Constraints. In Engineering within Ecological Constraints; Schulze, P.C., Ed.; National Academy Press: Washington, DC, USA, 1996; pp. 111-128. [CrossRef]

13. Wilkinson, M.; Quinn, P.; Barber, N.; Jonczyk, J. A framework for managing runoff and pollution in the rural landscape using a Catchment Systems Engineering approach. Sci. Total Environ. 2014, 468-469, 1245-1254. [CrossRef] [PubMed]

14. Hewett, C.; Mark E.; Wilkinson, M.; Jonczyk, J.; Quinn, P. Catchment Systems Engineering: An Holistic Approach to Catchment Management. WIREs Water 2019, In press.

15. Eggermont, H.; Balian, E.; Azevedo, M.; Beumer, V.; Brodin, T.; Claudet, J.; Fady, B.; Grube, M.; Keune, H.; Lamarque, P.; et al. Nature-based Solutions: New Influence for Environmental Management and Research in Europe. GAIA 2015, 24, 243-248. [CrossRef]

16. Nesshöver, C.; Assmuth, T.; Irvine, K.N.; Rusch, G.M.; Waylen, K.A.; Delbaere, B.; Haase, D.; Jones-Walters, L.; Keune, H.; Kovacs, E.; et al. The science, policy and practice of nature-based solutions: An interdisciplinary perspective. Sci. Total Environ. 2017, 579, 1215-1227. [CrossRef] [PubMed]

17. Howgate, O.R.; Kenyon, W. Community cooperation with natural flood management: A case study in the Scottish Borders. Area 2009, 41, 329-340. [CrossRef]

18. Forbes, H.; Ball, K.; McLay, F. Natural Flood Management Handbook; Technical Report; Scottish Environmental Protection Agency: Edinburgh, UK, 2015.

19. Lane, S.N. Natural flood management. WIREs Water 2017, 4, e1211. [CrossRef]

20. Mahmoud, N.; Selman, P. Natural Infrastructure Concept in Arid Regions: Two Case Studies in Egyptian Context. Int. J. Sustain. Dev. Plan. 2011, 6, 336-359. [CrossRef]

21. Bridges, T.S.; Lillycrop, J.; Wilson, J.; Fredette, T.; Suedel, B.; Banks, C.; Russo, E. Engineering with nature promotes triple-win outcomes. Terra Aqua 2014, 135, 17-23.

22. Ngai, R.; Wilkinson, M.; Nisbet, T.; Harvey, R.; Addy, S.; Burgess-Gamble, L.; Rose, S.; Maslen, S.; Nicholson, A.; Page, T.; et al. Working with Natural Processes Evidence Directory: Literature Review; Technical Report; Environment Agency: Bristol, UK, 2017.

23. Tzoulas, K.; Korpela, K.; Venn, S.; Yli-Pelkonen, V.; Kaźmierczak, A.; Niemela, J.; James, P. Promoting ecosystem and human health in urban areas using Green Infrastructure: A literature review. Landsc. Urban Plan. 2007, 81, 167-178. [CrossRef]

24. Everett, G.; Lawson, E.; Lamond, J. Green infrastructure and urban water management. In Handbook on Green Infrastructure: Planning, Design and Implementation; Sinnett, D., Burgess, S., Smith, N., Eds.; Edward Elgar: Cheltenham, UK, 2015; Chapter 3, pp. 50-66. [CrossRef] 
25. Everett, G.; Lamond, J.; Morzillo, A.T.; Chan, F.K.S.; Matsler, A.M. Sustainable drainage systems: Helping people live with water. Proc. Inst. Civil Eng. 2015, 169, 94-104. [CrossRef]

26. Thorne, C.; Lawson, E.; Ozawa, C.; Hamlin, S.; Smith, L. Overcoming uncertainty and barriers to adoption of Blue-Green Infrastructure for urban flood risk management. J. Flood Risk Manag. 2018, 11, S960-S972. [CrossRef]

27. Wilkinson, M.E.; Quinn, P.F.; Welton, P. Runoff management during the September 2008 floods in the Belford catchment, Northumberland. J. Flood Risk Manag. 2010, 3, 285-295. [CrossRef]

28. Metcalfe, P.; Beven, K.; Hankin, B.; Lamb, R. A modelling framework for evaluation of the hydrological impacts of nature-based approaches to flood risk management, with application to in-channel interventions across a 29-km² scale catchment in the United Kingdom. Hydrol. Process. 2017, 31, 1734-1748. [CrossRef]

29. Wilkinson, M.E.; Addy, S.; Quinn, P.F.; Stutter, M. Natural flood management: Small-scale progress and larger-scale challenges. Scott. Geogr. J. 2019, 135, 23-32. [CrossRef]

30. Quinn, P.; O’Donnell, G.; Nicholson, A.; Wilkinson, M.; Owen, G.; Jonczyk, J.; Barber, N.; Mardwick, M.; Davies, G. Potential Use of Runoff Attenuation Features in Small Rural Catchments for Flood Mitigation; Technical Report; Newcastle University: Newcastle upon Tyne, UK, 2013.

31. Young, W.J. Flume study of the hydraulic effects of large woody debris in lowland rivers. Regul. Rivers Res. Manag. 1991, 6, 203-211. [CrossRef]

32. Shields, F.D.; Morin, N.; Cooper, C.M. Large Woody Debris Structures for Sand-Bed Channels. J. Hydraul. Eng. 2004, 130, 208-217. [CrossRef]

33. Manners, R.B.; Doyle, M.W.; Small, M.J. Structure and hydraulics of natural woody debris jams. Water Resour. Res. 2007, 43. [CrossRef]

34. Bennett, S.J.; Ghaneeizad, S.M.; Gallisdorfer, M.S.; Cai, D.; Atkinson, J.F.; Simon, A.; Langendoen, E.J. Flow, turbulence, and drag associated with engineered log jams in a fixed-bed experimental channel. Geomorphology 2015, 248, 172-184. [CrossRef]

35. Cabaneros, S.; Danieli, F.; Formetta, G.; Gonzalez, R.; Grinfield, M.; Hankin, B.; Hewitt, I.; Johnstone, T.; Kamilova, A.; Kovacs, A.; et al. JBA Trust Challenge: A Risk-based Analysis of Small Scale, Distributed, "Nature-Based" Flood Risk Management Measures Deployed on River Networks; Technical Report; Maths Foresees: Leeds, UK, 2018.

36. Dixon, S.J.; Sear, D.A.; Odoni, N.A.; Sykes, T.; Lane, S.N. The effects of river restoration on catchment scale flood risk and flood hydrology. Earth Surf. Process. Landf. 2016, 41, 997-1008. [CrossRef]

37. Nyssen, J.; Pontzeele, J.; Billi, P. Effect of beaver dams on the hydrology of small mountain streams: Example from the Chevral in the Ourthe Orientale basin, Ardennes, Belgium. J. Hydrol. 2011, 402, 92-102. [CrossRef]

38. Gallisdorfer, M.S.; Bennett, S.J.; Atkinson, J.F.; Ghaneeizad, S.M.; Brooks, A.P.; Simon, A.; Langendoen, E.J. Physical-scale model designs for engineered log jams in rivers. J. Hydron.-Environ. Res. 2014, 8, 115-128. [CrossRef]

39. Bradshaw, S. Leaky Woody Dams-What Are the Differences and What Works Best? 2017. Available online: http:/ / slowtheflow.net/leaky-woody-dams-what-are-the-differences-and-what-works-best/ (accessed on 28 March 2019).

40. Yorkshire Dales Rivers Trust. Leaky Dams-Slowing the Movement of Water. 2018. Available online: http://www.yorkshiredalesriverstrust.com/wp-content/uploads/2018/01/NaturalFlood-Management-Techniques-Leaky-Dams.pdf (accessed on 22 June 2019).

41. Brooks, A.; Abbe, T.; Cohen, T.; Marsh, N.; Mika, S.; Boulton, A.; Broderick, T.; Borg, D.; Rutherfurd, I. Design Guidelines for the Reintroduction of Wood into Australian Streams; Land \& Water Australia: Canberra, Australia, 2006.

42. Environment Agency. Working with Natural Processes: One Page Summaries. 2017. Available online: https: / / www.gov.uk/government/publications/working-with-natural-processes-to-reduce-flood-risk (accessed on 3 July 2019).

43. Bokhove, O.; Kelmanson, M.; Kent, T. On Using Flood-Excess Volume to Assess Natural Flood Management, Exemplified for Extreme 2007 and 2015 Floods in Yorkshire. 2018. Available online: https:/ / eartharxiv.org/ 87z6w / (accessed on 6 December 2019).

44. Slow the Flow Calderdale. Projects: What Our Volunteers Have Achieved So Far. 2019. Available online: http:/ / slowtheflow.net/ (accessed on 14 November 2019). 
45. Nisbet, T.; Roe, P.; Marrington, S.; Thomas, H.; Broadmeadow, S.; Valatin, G. Defra FCERM Multi-Objective Flood Management Demonstration Project; Technical Report; Defra: London, UK, 2015.

46. Slowing the Flow Partnership. Slowing the Flow Partnership Briefing: Boxing Day 2015 Flood Event; Technical Report; Forest Research: Farnham, UK, 2016.

47. Thomas, H.; Nisbet, T. Modelling the hydraulic impact of reintroducing large woody debris into watercourses. J. Flood Risk Manag. 2012, 5, 164-174. [CrossRef]

48. Clark, A. Slowing the Flow in Hebden Bridge: A Pilot Study Using Small Weirs. Master's Thesis, University of Leeds, Leeds, UK, 2016.

49. Pattison, I.; Lane, S.N.; Hardy, R.J.; Reaney, S.M. The role of tributary relative timing and sequencing in controlling large floods. Water Resour. Res. 2014, 50, 5444-5458. [CrossRef]

50. Hankin, B.; Burgess-Gamble, L.; Bentley, S.; Rose, S. How to Model and Map Catchment Processes When Flood Risk Management Planning; Technical Report; Environment Agency: Bristol, UK, 2016.

51. Hutton Institute. Modelling the Hydrological Effects of in-Channel Leaky Barriers for Flood Risk and Natural Flood Management. 2019. Available online: https://www.hutton.ac.uk/research/srp2016-21/ wp122/modelling-hydrological-effects-channel-leaky-barriers-flood-risk-and-natural-flood (accessed on 3 December 2019).

52. Norbury, M.; Shaw, D.; Jones, P. Combining Hydraulic Modelling with Partnership Working: Towards a Practical Natural Flood Management Approach. Proc. Inst. Civil Eng.-Eng. Sustain. 2018, 1-43. [CrossRef]

53. Odini, N.A.; Lane, S.N. Assessment of the Impact of Upstream Land Management Measures on Flood Flows in Pickering Beck Using OVERFLOW; Technical Report; Durham University: Durham, UK, 2010.

54. Kitts, D. The Hydraulic and Hydrological Performance of Large Wood Accumulation in a Low-Order Forest Stream. Ph.D. Thesis, University of Southampton, Southampton, UK, 2010.

55. Rasche, D.; Reinhardt-Imjela, C.; Schulte, A.; Wenzel, R. Hydrodynamic simulation of the effects of stable in-channel large wood on the flood hydrographs of a low mountain range creek, Ore Mountains, Germany. Hydrol. Earth Syst. Sci. 2019, 23, 4349-4365. [CrossRef]

56. Addy, S.; Wilkinson, M.E. Representing natural and artificial in-channel large wood in numerical hydraulic and hydrological models. WIREs Water 2019, 6, e1389. [CrossRef]

57. Sholtes, J.; Doyle, M. Effect of Channel Restoration on Flood Wave Attenuation. J. Hydraul. Eng. 2011, 137, 196-208. [CrossRef]

58. Valverde, R. Roughness and Geometry Effects of Engineered Log Jams on 1-D Flow Characteristics. Master's Thesis, Oregon State University, Corvallis, OR, USA, 2013.

59. Milledge, D.; Odoni, N.; Allott, R.; Evans, M.; Pilkington, M.; Walker, J. Annex 6. Flood risk modelling. In Restoration of Blanket Bogs; Flood Risk Reduction and Other Ecosystem Benefits; Pilkington, M., Ed.; Moors for the Future Partnership: Edale, UK, 2015.

60. Wallerstein, N.; Alonso, C.; Bennett, S.; Thorne, C. Distorted Froude-scaled flume analysis of large woody debris. Earth Surf. Process. Landf. 2001, 26, 1265-1283. [CrossRef]

61. Samani, J.M.V.; Mazaheri, M. Combined flow over weir and under gate. J. Hydraul. Eng. 2009, 135, $224-227$. [CrossRef]

62. Swamee, P. Sluice-Gate Discharge Equations. J. Irrig. Drain. Eng. 1992, 118, 56-60. [CrossRef]

63. Negm, A.A.M.; Al-Brahim, A.M.; Alhamid, A.A. Combined-free flow over weirs and below gates. J. Hydraul. Res. 2002, 40, 359-365. [CrossRef]

64. Negm, A.A.M.; Al-Brahim, A.M.; Alhamid, A.A.; Altan Sakarya, B.; Aydin, I.; Ger, A.M. Combined-free flow over weirs and below gates. J. Hydraul. Res. 2004, 42, 559-562. [CrossRef]

65. Duru, A. Numerical Modelling of Contracted Sharp Crested Weirs. Master's Thesis, Middle East Technical University, Ankara, Turkey, 2014.

66. Toro, E.F. Shock-Capturing Methods for Free-Surface Shallow Flows; John Wiley: New York, NY, USA, 2001.

67. Toro, E.F. Riemann Solvers and Numerical Methods for Fluid Dynamics: A Practical Introduction; Springer: Heidelberg/Berlin, Germany, 2009.

68. Liang, Q.; Marche, F. Numerical resolution of well-balanced shallow water equations with complex source terms. Adv. Water Resour. 2009, 32, 873-884. [CrossRef]

69. Harten, A.; Lax, P.D.; van Leer, B. On Upstream Differencing and Godunov-Type Schemes for Hyperbolic Conservation Laws. SIAM Rev. 1983, 25, 35-61. [CrossRef] 
70. Glenis, V.; Kutija, V.; Kilsby, C. A fully hydrodynamic urban flood modelling system representing buildings, green space and interventions. Environ. Model. Softw. 2018, 109, 272-292. [CrossRef]

71. Van Leer, B. MUSCL, A New Approach to Numerical Gas Dynamics. In Proceedings of the Second European Conference on Computational Physics, Garching, 27-30 April 1976.

72. Cozzolino, L.; Cimorelli, L.; Covelli, C.; Della Morte, R.; Pianese, D. The analytic solution of the Shallow-Water Equations with partially open sluice-gates: The dam-break problem. Adv. Water Resour. 2015, 80, 90-102. [CrossRef]

73. Bogoni, M.; Canestrelli, A.; Lanzoni, S. Finite volume modelling of a stratified flow with the presence of submerged weirs. J. Appl. Water Eng. Res. 2015, 3, 43-52. [CrossRef]

74. Lin, C.; Yen, J.; Tsai, C. Influence of Sluice Gate Contraction Coefficient on Distinguishing Condition. J. Irrig. Drain. Eng. 2002, 128, 249-252. [CrossRef]

75. Henry, H.R. Discussion on 'Diffusion of submerged jets'. Trans. Am. Soc. Civil Eng. 1950, 115, 639-697.

76. Sepulveda, C.; Gomez, M.; Rodellar, J. Benchmark of Discharge Calibration Methods for Submerged Sluice Gates. J. Irrig. Drain. Eng. 2009, 135, 676-682. [CrossRef]

77. Villemonte, J.R. Submerged weir discharge studies. Eng. News-Rec. 1947, 139, 54-56.

78. Franzini, F.; Hoedenaeken, D.; Soares-Frazão, S. Modeling the Flow Around Islands in Rivers Using a One-Dimensional Approach; Gourbesville, P., Cunge, J., Caignaert, G., Eds.; Advances in Hydroinformatics; Springer: Singapore, 2018; pp. 127-143. [CrossRef]

79. Delestre, O.; Lucas, C.; Ksinant, P.A.; Darboux, F.; Laguerre, C.; Vo, T.N.T.; James, F.; Cordier, S. SWASHES: A compilation of shallow water analytic solutions for hydraulic and environmental studies. Int. J. Numer. Methods Fluids 2013, 72, 269-300. [CrossRef]

80. Tuoi, V. One-Dimensional Saint-Venant System. Master's Thesis, University of Orleans, Orleans, France, 2008.

81. Roberts, S.; Nielsen, O.; Gray, D.; Sexton, J.; Davies, G. ANUGA User Manual Release 2.0.3; Technical Report; Geoscience Australia: Canberra, Australia, 2019.

(C) 2020 by the authors. Licensee MDPI, Basel, Switzerland. This article is an open access article distributed under the terms and conditions of the Creative Commons Attribution (CC BY) license (http:/ / creativecommons.org/licenses/by/4.0/). 